\title{
Promotion of ubiquitination-dependent survivin destruction contributes to xanthohumol-mediated tumor suppression and overcomes radioresistance in human oral squamous cell carcinoma
}

\author{
Ming Li \\ Hunan University of Chinese Medicine \\ Feng Gao \\ Central South University \\ Xinfang Yu \\ Central South University \\ Qiung Zhao \\ Hunan University of Chinese Medicine

\section{Li Zhou}

Central South University

Wenbin Liu

Central South University

Wei Li ( $\square$ weilix@csu.edu.cn )

Central South University https://orcid.org/0000-0002-7267-6494

\section{Research}

Keywords: Oral squamous cell carcinoma; Xanthohumol; Ubiquitination; Fbxl7

Posted Date: April 6th, 2020

DOI: https://doi.org/10.21203/rs.3.rs-20813/v1

License: @ (i) This work is licensed under a Creative Commons Attribution 4.0 International License.

Read Full License

Version of Record: A version of this preprint was published at Journal of Experimental \& Clinical Cancer Research on May 14th, 2020. See the published version at https://doi.org/10.1186/s13046-020-01593-z. 


\section{Abstract}

Background: Overexpression of survivin plays a crucial role in the maintaining unlimited cell growth, apoptosis suppression, and correlates with poor prognosis in human malignancies.

Methods: A natural product library was used for natural compound screening through MTS assay. The expression of survivin in oral squamous cell carcinoma (OSCC) and the inhibitory effect of xanthohumol $(\mathrm{XN})$ on OSCC were examined through methods of anchorage-dependent and -independent growth assays, immunoblot, immunofluorescence, immunohistochemical staining, ubiquitination analysis, coimmunoprecipitation assay, CRISPR-Cas9-based gene knockout, and xenograft experiment.

Results: Survivin is highly expressed in OSCC cells and patient-derived tissues, and required for OSCC cell growth in vitro and in vivo. With a natural compound screening, we identified that xanthohumol exhibited a significant anti-tumor effect against OSCC cells through inhibiting survivin protein. Xanthohumol suppressed anchorage-dependent and independent cell growth and delayed in vivo tumor development of OSCC cells. Xanthohumol inhibited the Akt-Wee1-CDK1 signaling, which in turn decreased survivin phosphorylation on Thr34, and facilitated E3 ligase Fbxl7-mediated survivin ubiquitination. Xanthohumol alone or in combination with radiation overcame radioresistance in OSCC xenograft tumors.

Conclusion: Our findings indicate that targeting survivin for degradation might a promising strategy for OSCC treatment.

Keywords: Oral squamous cell carcinoma; Xanthohumol; Ubiquitination; Fbxl7

\section{Background}

Oral cancer is one of the most common cancers worldwide, accounting for $2 \%$ of all cancer cases. Over $90 \%$ of oral malignancies were diagnosed as oral squamous cell carcinoma (OSCC), which arise from the epithelial mucosa of the oral cavity (1-3). Beyond genetic susceptibility caused by gene mutation, multiple environmental factors have been considered to contribute to the initiation of OSCC (4). Tobacco, alcohol, and betel nut chewing remain the major culprits with a well-established synergistic effect for the tumorigenesis of OSCC. The highest incidence of OSCC is observed in South Asian countries and regions, such as India, Sri Lanka, and the south-central of China, which are caused by the high rates of cigarette smoking and areca nut use in these areas (5-7). Although the improvements in early diagnosis and surgical treatment over the past decades, OSCC usually progresses rapidly and presents high mortality rates, especially in patients with an advanced stage, and no targeted therapy is used in clinic for OSCC treatment currently $(3,6-9)$. Thus, a better understanding of the mechanisms of OSCC oncogenesis and development of novel anti-tumor targets and drugs, are still the urgent demand for OSCC treatment.

Survivin is an evolutionarily conserved eukaryotic protein that plays a critical role in cell cycle G2/M transition and apoptosis inhibition (10). Together with the Aurora B kinase, survivin constitutes an integral component of chromosomal passenger complex (CPC) which guarantees proper chromosomes 
and segregation during mitosis $(10,11)$. Beyond the key role in cell division, as a member of the inhibitor of apoptosis protein family (IAPs), survivin is frequently overexpressed in human cancers and confers the unlimited cell proliferation and apoptosis resistance (11-14). Previous reported showed that survivin is predominantly localized in the cytoplasm of cancer cells and is generally believed to function as apoptotic suppressor to maintain survival of cancer cells. In contrast, the smaller fraction of nuclear localized survivin is considered to act as a component of CPC complex to promote cell cycle progression, suggesting that the different subcellular pools of survivin exhibit distinct biological functions (13-16). Thus, as an oncoprotein that is both essential for mitosis and apoptosis inhibition, survivin seemed a promising novel target for anti-cancer treatment. Although overexpression of survivin is positively correlated with poor prognosis in multiple human cancers, the function of survivin in human OSCC remains undefined.

In this study, we investigate the biological function of survivin in human OSCC cells. With a compound screening, we identified the natural product, xanthohumol, as a potential survivin inhibitor for OSCC treatment. We determined the anti-tumor effect of xanthohumol in OSCC cells and elucidate the underlying mechanisms using the in vitro and in vivo models.

\section{Materials And Methods}

Reagents and cell culture. Chemical reagents, including DMSO, SDS, $\mathrm{NaCl}$, and Tris base, were purchased from Sigma-Aldrich (St. Louis, MO). MG132 and cycloheximide (CHX) were obtained from Thermo Fisher Scientific (Waltham, MA). The DMEM, RPMI-1640 medium, and Fetal Bovine Serum (FBS) for cell culture were purchased from Invitrogen (Grand Island, NY). Human oral squamous cell carcinoma (OSCC) cells, including CAL27, SCC15, SCC25, and SCC9 were purchased from American Type Culture Collection (ATCC, Manassas, VA). The cells were maintained according to ATCC protocols in a $37^{\circ} \mathrm{C}$ humidified incubator with $5 \% \mathrm{CO}_{2}$. The ionizing radiation acquired resistance cell lines CAL27-IR and SCC25-IR were established in our laboratory by exposing CAL27 and SCC25 cells to gradually increasing dose of ionizing radiation for approximately 6 months. Immortalized oral epithelial cell hTERT-OME was purchased from Applied Biological Materials (ABM) Inc. (Richmond, BC, Canada). All cells were subjected to mycoplasma analysis every two months. Primary antibodies against Survivin (\#2808), cleaved-PARP (\#9532), VDAC1 (\#4661), Bax (\#14796), cleaved-caspase 3 (\#9664), cytochrome C (\#11940), ubiquitin (\#43124), $\beta$-actin (\#3700), ubiquitin (\#3936), p-Survivin Thr34 (\#8888), a-tubulin (\#3873), p-Akt Ser473 (\#4060), p-Wee1 Ser642 (\#4910), His-tag (\#12698), HA-tag (\#2367), p-CDK1 Tyr15 (\#4539), and p-CDK1 Thr161 (\#9114) were obtained from Cell Signaling Technology, Inc. (Beverly, MA). Antibodies against Ki67 (ab16667) and FbxL7 (\#ab59149) were purchased from Abcam (Cambridge, UK). Flag-tag (F3165) antibody was obtained from Sigma Aldrich (St. Louis, MO). Lipofectamine ${ }^{\circledR} 2000$ (Thermo Fisher Scientific) was used for plasmid transfection following the manufacturer's instructions.

MTS assays. MTS assay was performed as described previously (17). Briefly, human OSCC cells were seeded in 96 -well plates at a concentration of $2 \times 10^{3} /$ well. Cells were treated with DMSO control or 
xanthohumol for various time points, cell viability was determined by MTS assay (G3581, Promega, Madison, $\mathrm{WI})$.

Anchorage-independent cell growth. The anchorage-independent cell growth assay was performed as described previously (18). Briefly, the Eagle's basal medium containing 10\% FBS, $0.6 \%$ agar, and different concentration of xanthohumol was loading to a six-well plate as an agar base. Human OSCC cells were counted at the concentration of 8,000 cells $/ \mathrm{ml}$ and seeded into 6 -well plates with $0.3 \%$ Basal Medium Eagle agar containing $10 \% \mathrm{FBS}$ and xanthohumol. The cultures were maintained at $37^{\circ} \mathrm{C}$ in a $5 \% \mathrm{CO}_{2}$ incubator for 2 weeks and colonies were counted.

Western blotting. Whole-cell extract (WCE) was prepared with RIPA buffer (\#PI89901, Thermo Fisher Scientific) supplemented with protease inhibitors and concentrated by BCA protein assay. Western blotting was performed as previously described (19). Briefly, A total of $30 \mu \mathrm{g}$ WCE was mixed with loading buffer and boiled at $95^{\circ} \mathrm{C}$ for $5 \mathrm{~min}$, followed by SDS-PAGE electrophoresis and electrotransfer. The nonfat milk (5\%) was used for membrane blocking at room temperature for $30 \mathrm{~min}$ and the membrane was incubated with the primary antibody at $4^{\circ} \mathrm{C}$ overnight. After incubation with anti-rabbit/mouse IgG HRP second antibody, the target protein was visualized by chemiluminescence.

Immunohistochemical staining (IHC). The tissues from xenograft tumors were fixed in $10 \%$ neutralbuffered formalin and subjected to immunohistochemical staining as described previously (20). First, the tissue slides were deparaffinized, followed by rehydration using various concentrations of ethanol. Antigen retrieval was performed by boiling the slides with the sodium citrate buffer $(10 \mathrm{mM}, \mathrm{pH} 6.0)$ for 10 min. The slides were incubated with $3 \% \mathrm{H}_{2} \mathrm{O}_{2}$ in methanol for 10 min to deactivation of endogenous peroxidase. After washing with PBS, slides were blocked with 50\% goat serum albumin in PBS for $1 \mathrm{~h}$ at room temperature, followed by incubation with primary antibody $\left(4^{\circ} \mathrm{C}\right.$, overnight) and second antibody (room temperature, $45 \mathrm{~min}$ ) in a humidified chamber. The target protein was visualized by DAB substrate and hematoxylin was used for counterstaining.

Natural compound screening. The 70 compounds of interest were selected from the Natural Product Library (Cat. No. L1400-01/02) from Selleck Chemicals (Houston, TX). CAL27 cells were seeded in a 96well plate. After overnight incubation, cells were treated with $1 \mu \mathrm{M}$ of DMSO (control) or natural compounds for $48 \mathrm{~h}$. Cell viability was examined by the MTS assay. Tested compounds are listed in Table S1.

Generation of survivin knockout stable cell lines. Two different single-guide RNAs (sgRNAs) were used to generate CRISPR-Cas9-based survivin knockout constructs (sgSurvivin\#1forward, 5'CAGTTTGAAGAATTAACCCT-3', reverse, 5'-AGGGTTAATTCTTCAAACTG-3', sgSurvivin\#2 forward, 5'GAACATAAAAAGCATTCGTC-3', reverse, 5'-GACGAATGCTTTTTATGTTC-3'). The sgSurvivin plasmid was transiently transfected to the OSCC cells. Puromycin $(1 \mu \mathrm{g} / \mathrm{mL})$ was added to cell culture medium and maintained for 3 weeks for signal clone selection. The Fbxl7 siRNA (sc-62306), Akt1/2 siRNA (sc-43609), 
and siCtrl (sc-37007) were purchased from Santa Cruz Biotechnology (Dalla, TX). The primers for survivin qRT-PCR analysis is forward: CCACTGAGAACGAGCCAGACTT, reverse: GTATTACAGGCGTAAGCCACCG.

Ubiquitination analysis. The Ubiquitination analysis was performed as described previously (21). Briefly, for endogenous ubiquitination detection, cells were lysed with modified RIPA buffer (20 mM NAP, pH7.4, $150 \mathrm{mM} \mathrm{NaCl}, 1 \%$ Triton, $0.5 \%$ Sodium-deoxycholate, and 1\% SDS) supplemented with $10 \mathrm{mM} \mathrm{N}$ Ethylmaleimide (NEM) and protease inhibitors. The lysates were sonicated for $30 \mathrm{~s}$, boiled at $95^{\circ} \mathrm{C}$ for 15 min, and diluted with $0.1 \%$ SDS containing RIPA buffer, then centrifuged at $16000 \times \mathrm{g}$ for $15 \mathrm{~min}$ at $4^{\circ} \mathrm{C}$. The supernatant was subjected to IP with survivin antibody, survivin ubiquitination was determined by IB analysis. For Nickel pull-down assay, cell lysates were prepared with lysis buffer $(6 \mathrm{M}$ guanidine- $\mathrm{HCl}, 0.1$ $\mathrm{M} \mathrm{Na} 2 \mathrm{HPO} 4 / \mathrm{NaH} 2 \mathrm{PO} 4,0.01 \mathrm{M}$ Tris/HCl, $\mathrm{pH}$ 8.0, 5mM imidazole, and 10mMß-mercaptoethanol) supplemented with protease inhibitors and $10 \mathrm{mM} \mathrm{N}$-Ethylmaleimide (NEM). The lysates were sonicated for $30 \mathrm{~s}$, followed by incubation with $50 \mathrm{ml}$ Ni-NTA-agarose (QIAGEN Inc, Valencia, CA) for $4 \mathrm{~h}$ at room temperature. The beads were washed with specific washing buffer and boiled with $2 \times$ SDS loading buffer containing $200 \mathrm{mM}$ imidazole and subjected to western blotting.

Immunofluorescence (IF). Cells in a chamber slide and treated with vehicle control, XN (5 $\mu \mathrm{M}, 24 \mathrm{~h}), \mathrm{IR}(4$ Gy), or a XN and IR combination. Cells were maintained in the incubator for another $72 \mathrm{~h}$. Cells were fixed with $4 \%$ paraformaldehyde and permeabilized in $0.5 \%$ Triton X-100 for $20 \mathrm{~min}$, followed by blocking in $5 \%$ BSA for $1 \mathrm{~h}$ and overnight incubation with $\mathrm{\gamma}-\mathrm{H} 2 \mathrm{AX}$ antibody at $4^{\circ} \mathrm{C}$ in a humidified chamber . Alexa Fluor 488 dye-labeled anti-rabbit IgG was used as the secondary antibody. Nuclei were counterstained with DAPI (cat. \#P36935, Thermo Fisher Scientific). The following antibodies were used for IF: y-H2AX (cat. \#ab11174, 1:100), goat anti-rabbit IgG Alexa Fluor 488 (cat. \#ab150077, 1:500).

Plate colony formation assay. The cells were treated with vehicle control, XN, IR, or a XN and IR combination and seeded into a $6-\mathrm{cm}$ plate $(400$ cells/well). The cultures were maintained for 2 weeks at $37^{\circ} \mathrm{C}$ in a $5 \% \mathrm{CO}_{2}$ incubator. The colonies were fixed with $4 \%$ paraformaldehyde, stained with $0.5 \%$ crystal violet, and counted under a microscope. Three independent experiments were performed as indicated.

In vivo tumor growth assay. The in vivo animal study was approved by the Institutional Animal Care and Use Committee (IACUC) of Central South University (Changsha, China). $\left(2 \times 10^{6}\right)$ cells were s.c.injected into the 6-week-old athymic nude mice $(n=6)$ at the right flank to generate the xenograft mouse model. Compound treatment was initiated when tumor volume reached at $100 \mathrm{~mm}^{3}$. Xanthohumol $(10 \mathrm{mg} / \mathrm{kg})$ was administrated by i.p. injection every two days, whereas the control mice were treated with vehicle control. For irradiation treatment, the tumor bearing mice were randomly divided into four groups $(n=6)$ : 1, vehicle control ( $0.5 \%$ dimethyl sulfoxide, $100 \mathrm{~mL}$ /every two days, i.p.); 2, local ionizing radiation (2 Gy/ twice per week); 3, Xanthohumol (10 mg/kg/ every two days, i.p.); 4, Xanthohumol (10 mg/kg/ every two days, i.p.) + local ionizing radiation ( $2 \mathrm{~Gy} /$ twice per week). Tumor volume was recorded with and determined with the formula: length $\times$ width $\times$ width/2. Tumor mass was subjected to IHC staining. 
Blood analysis. The EDTA-coated tubes were used for Mouse blood collection by cardiac puncture. The red blood cells (RBC), hemoglobin ( $\mathrm{Hb}$ ), white blood cells (WBC), alanine aminotransferase (ALT), aspartate aminotransferase (AST), and blood urea nitrogen (BUN) were analyzed at the Laboratory of the Third Xiangya Hospital of Central South University (Changsha, Hunan, China).

Statistical analysis. The statistical analysis was conducted with GraphPad Prism 5 (San Diego, CA). The Student's t-test or one-way ANOVA was used to evaluate the difference between tested groups, and a probability value of $p<0.05$ was used as the criterion for statistical significance. The experiment was performed triplicate, and all quantitative data are expressed as mean $\pm \mathrm{sd}$.

\section{Results}

\section{Survivin is highly expressed in OSCC tissues and cancer cells}

To determine the role of survivin in human OSCC, we performed immunoblotting (IB) to examine the expression of survivin in human OSCC tissues. The result showed that the protein level of survivin is significantly upregulated in OSCC tissues when compared to the paired adjacent non-tumor tissues (Figure 1A). Furthermore, as compared to the immortalized oral epithelial cell, survivin was expressed at a relatively higher level in all tested OSCC cell lines (Figure 1B). These results indicate that high level of survivin might play a crucial role in the oncogenesis of OSCC. Using the CRISPR-Cas9 based gene knockout technology, we constructed survivin stable knockout CAL27 and SCC25 cells. The MTS data revealed that knockout of survivin inhibited cell viability significantly in CAL27 and SCC25 cells (Figure 1C). Moreover, the colony formation of survivin depletion OSCC cells was decreased robustly (Figure 1D), suggesting that survivin deficiency attenuated both anchorage-dependent and -independent cell growth of OSCC cells. We next performed the xenograft tumor model to determine the effect of survivin on in vivo tumor development of OSCC cells. Our data revealed that depletion of survivin caused a significant reduction of tumor volume and tumor weight in CAL27-derived xenograft tumors (Figure 1E-1G). Consistently, a similar inhibitory effect was observed in SCC25 xenograft tumors (Figure 1H-1J). These results support the notion that survivin is overexpressed in OSCC tissues and cell lines, knockout of survivin reduces the tumorigenic properties of OSCC cells.

\section{Xanthohumol is a candidate compound for OSCC inhibition}

To discover natural products (Table S1) that can inhibit survivin and OSCC, we screened a natural compound library containing 70 compounds of interest by MTS assay. Our data showed that only xanthohumol caused a reduction of cell viability in CAL27 cells by over $30 \%$ at a single dose of $1 \mu \mathrm{M}$ (Figure 2A and 2B). We therefore focus on xanthohumol for further study. To determine the toxicity of xanthohumol on normal cells, we treated the immortalized human keratinocyte cell HaCat for various time points. The result revealed that $72 \mathrm{~h}$ xanthohumol treatment did not cause a significant decrease in cell viability of $\mathrm{HaCaT}$ cells while the concentration less than $10 \mu \mathrm{M}$ (Figure $2 \mathrm{C}$ ), indicating that xanthohumol is well-tolerated in immortalized non-tumor cells. We next validate the inhibitory effect of xanthohumol on a panel of human OSCC cells. Xanthohumol inhibits the cell viability of SCC25, SCC9, 
and CAL27 cells time- and dose-dependently (Figure 2D). Treatment with $5 \mu \mathrm{M}$ xanthohumol for $72 \mathrm{~h}$ caused a reduction of cell viability over $70 \%$ in all of these examined cells (Figure 2D). Furthermore, the anchorage-independent growth assay showed that xanthohumol suppressed colony formation of OSCC cells significantly, and $5 \mu \mathrm{M}$ xanthohumol decreased the efficacy of colony formation over $90 \%$ (Figure $2 \mathrm{E}$ ). Taken together, these results indicate that xanthohumol is a candidate compound that exhibits significantly anti-tumor effect in OSCC cells.

\section{Xanthohumol downregulates survivin expression and causes mitochondrial apoptosis in OSCC cells}

To determine whether the anti-tumor effect of xanthohumol on OSCC cells is dependent on survivin downregulation, we examined survivin expression in xanthohumol-treated OSCC cells. The IB data showed that xanthohumol decreased the protein level of survivin in SCC25, SCC9, and CAL27 cells dosedependently (Figure 3A). Moreover, the cleaved-PARP and -caspase 3 were increased substantially, indicating that the activation of apoptosis (Figure $3 \mathrm{~A}$ ). Indeed, treatment with xanthohumol-upregulated the activity of caspase 3 (Figure 3B). By isolation of the subcellular fractions from SCC25 (Figure 3C) and CAL27 (Figure 3D), we found that xanthohumol dose-dependently promoted the protein level of cytochrome $\mathrm{C}$ in the cytosolic fraction, whereas the expression of cytochrome $\mathrm{C}$ in mitochondrial fraction was reduced consistently (Figure 3C and 3D). Furthermore, xanthohumol increased the presence of Bax on mitochondria and decreased it in the cytoplasm (Figure 3C and 3D). This evidence indicates that xanthohumol activates the intrinsic apoptosis signaling. We next determined whether overexpression of survivin rescued xanthohumol-induced apoptosis. Our results revealed that ectopic overexpression of survivin compromised xanthohumol decreased cell viability (Figure 3E) in SCC25 cells. Consistently, the activity of cleaved-caspase 3 was reduced with survivin transfection (Figure 3F). In addition, the overexpression of survivin attenuated xanthohumol-induced upregulation of cleaved-caspase 3, -PARP (Figure 3G), and mitochondrial apoptosis (Figure 3H). These data suggest that downregulation of survivin is required for xanthohumol-induced intrinsic apoptosis in OSCC cells.

\section{Xanthohumol promotes Fbxl7-mediated survivin ubiquitination and degradation}

To determine the mechanism of how xanthohumol downregulates survivin expression, we first performed qRT-PCR to analyze the transcription of survivin after xanthohumol treatment. The result showed that the mRNA level of survivin was unaffected in xanthohumol-treated OSCC cells (Supplementary Figure 1). Importantly, the proteasome inhibitor, MG132, restored survivin expression (Figure 4A and B). Further study showed that xanthohumol shortened survivin half-life from $1.5 \mathrm{~h}$ to $45 \mathrm{~min}$. Moreover, treated with MG132 extended the half-life over $4 \mathrm{~h}$ with either xanthohumol treated or not (Figure 4C). These data suggest that xanthohumol decreased survivin expression is related to protein degradation. Indeed, the ubiquitination analysis revealed that treated with xanthohumol increased survivin ubiquitination in SCC25 cells (Figure 4D). The previous report demonstrated that Fbxl7 is an E3 ligase which required for survivin degradation (22). The IB result showed that ectopic overexpression of FbxI7 reduced survivin protein level dose-dependently in OSCC cells (Figure 4E). Moreover, the Co-IP results showed that xanthohumol enhanced the interaction between survivin and E3 ligase Fbxl7 (Figure 4F). To further 
validate surviving ubiquitination in OSCC cells we co-transfected survivin and Fbxl7 in SCC25 cells. The results revealed that Fbxl7 promoted survivin ubiquitination robustly, and treated with xanthohumol enhanced this process (Figure 4G). Consistently, knockdown of Fbxl7 by siRNA impaired xanthohumolinduced survivin ubiquitination in OSCC cells (Figure 4H), indicating that the E3 ligase Fbxl7 is required for xanthohumol-promoted survivin ubiquitination. The lysine residues (K) 90 and 91 are two ubiquitination sites which required for ubiquitin ligation (22). The ubiquitination analysis showed that double mutation of K90/91 substantially decreased xanthohumol-induced survivin ubiquitination when compare to survivin wild type (Figure 4I). In addition, the survivin K90/91R mutant exhibited a robust reduction of ubiquitination either treated with xanthohumol or not (Figure $4 \mathrm{~J}$ ). These results indicate that xanthohumol promotes survivin ubiquitination and degradation in an E3 ligase Fbx17-dependent manner.

\section{Xanthohumol-decreased survivin Thr34 phosphorylation is required for survivin ubiquitination}

Because the phosphorylation of survivin on Thr34 is required for the biological function and stability of survivin, we next determined whether xanthohumol regulates survivin phosphorylation. As shown in Figure 5A, xanthohumol inhibited survivin Thr34 phosphorylation dose-dependently. Interestingly, the IB data revealed that xanthohumol decreased the activation of Akt signaling. The phosphorylation of Akt on Ser473 was inhibited with xanthohumol treatment (Figure 5B). As the downstream target kinase of Akt, Wee1 phosphorylation was reduced coordinately (Figure 5B). The previous study showed that Aktdependent phosphorylation at Ser642 promotes the localization of Wee1 from nuclear to cytoplasmic, which is required for G2/M cell cycle arrest (23). Our current data found that xanthohumol reduced Wee1 phosphorylation on Ser642, indicating that the nuclear xanthohumol promoted Wee1 nuclear localization. Indeed, Wee1-mediated CDK1 phosphorylation on Tyr15 was increased robustly with xanthohumol treatment. However, the phosphorylation of CDK1 on Thr161, which was a marker of CDK1 activation, was reduced dose-dependently (Figure 5B). Moreover, knockdown of Akt by siRNA inhibited the phosphorylation of Wee1 (Ser642), CDK1 (Thr161), and survivin (Thr34), whereas the phosphorylation of CDK1 on Tyr15 was upregulated (Figure 5C). Furthermore, ectopic overexpression of constitutively activated Akt, Myr-Akt1, rescued xanthohumol-induced reduction of phosphorylation of Wee1 (Ser642), CDK1 (Thr161), and survivin (Thr34) (Figure 5D). Consistently, cell viability was increased in Myr-Akt1 transfected SCC25 cells (Figure 5E). Additionally, the activity of cleaved-caspase 3 was attenuated significantly (Figure 5F), and the protein level of cleaved-caspase 3 and -PARP were decreased (Figure 5G) with Myr-Akt1 overexpression. These results suggest that inhibition of Akt signaling was required for xanthohumol-induced survivin Thr34 phosphorylation suppression and apoptosis induction.

We next constructed survivin T34A mutant, in which the Thr 34 was mutant to Ala. The result showed that xanthohumol-induced a much stronger reduction of protein level of survivin T34A mutant (Figure $5 \mathrm{H}$ ). Moreover, the T34A mutation shortened the half-life of survivin from around $45 \mathrm{~min}$ to $15 \mathrm{~min}$ (Figure 5I). We further compared xanthohumol-induced ubiquitination of survivin WT and T34A. The result showed that mutation of T34 to Ala increased survivin ubiquitination substantially after xanthohumol treatment (Figure 5J). Strikingly, survivin WT, but not the T34A mutant, rescued cell viability 
(Figure 5K) and decreased cleaved-caspase activity (Figure 5L) in xanthohumol-treated survivin knockout cells. Collectively, our data suggest that the inhibition of phosphorylation is required for survivin ubiquitination and destruction in xanthohumol-treated OSCC cells.

\section{Xanthohumol suppresses in vivo tumor growth of OSCC cells}

To determine the in vivo anti-tumor efficacy of xanthohumol, we performed the xenograft mouse model. Our data showed that xanthohumol delayed the in vivo tumor development of CAL27- and SCC25-derived xenograft tumors significantly (Figure 6A-6F). Treatment with xanthohumol reduced the tumor volume (Figure 6A and 6B) and tumor weight (Figure $6 \mathrm{C}$ ) of CAL27 tumors, the tumor volume of the vehicletreated group was reached at around $600 \mathrm{~mm}^{3}$, whereas the tumor volume of xanthohumol-treated group was less than $200 \mathrm{~mm}^{3}$ (Figure 6A). A similar inhibitory effect was also observed in SCC25 xenograft tumors, and the tumor size of xanthohumol-treated group was significantly smaller than that of vehicletreated group (Figure 6D). The IHC data revealed that xanthohumol-treated xenograft tumors exhibited a significant reduction of Ki67, p-Akt, and survivin protein levels (Figure 6G).

To determine the in vivo toxicity of xanthohumol, we recorded the bodyweight of xanthohumol-treated mice. We found that xanthohumol did not cause a significant body weight loss (Figure $6 \mathrm{H}$ and $6 \mathrm{I}$ ). Moreover, blood analysis showed that xanthohumol did not affect the RBC and WBC counts. In addition, xanthohumol exhibited no significant toxicity to vital organ functions of bone marrow, kidney, and liver, as the $\mathrm{Hb}, \mathrm{AST}, \mathrm{ALT}$, and BUN in vehicle- and xanthohumol-treated mice was unaffected (Figure $6 \mathrm{~J}$ ). Overall, these data suggest that xanthohumol is a well-tolerated nature compound and suppresses in vivo tumor growth of OSCC cells.

\section{Xanthohumol overcomes radioresistance in OSCC cells}

To determine the crucial role of survivin in radioresistance, we examined the protein level of survivin in two pair of radioresistant OSCC cells, CAL27/CAL27-IR and SCC25/SCC25IR. The IB data showed that survivin is highly expressed in both radioresistant CAL27-IR and SCC25-IR cells (Figure 7A). Irradiation (4 Gy) significantly decreased the cell viability and colony formation of CAL27 and SCC25, but not that of the radioresistant cells (Figure 7B and 7C, Supplementary Figure 2A and 2B). Importantly, treatment with xanthohumol reduced the expression of survivin in CAL27-IR and SCC25-IR cells robustly (Figure 7D, Supplementary Figure 2C). In contrast, irradiation did not cause a significant decrease of survivin in radioresistant cells. Consistently, xanthohumol, but not single dose of irradiation, decreased the cell viability and colony formation of CAL27-IR and SCC25-IR cells (Figure 7E and 7F, Supplementary Figure $2 \mathrm{D}$ and $2 \mathrm{E}$ ). Furthermore, pretreated with xanthohumol significantly enhanced the anti-tumor effect of irradiation in these resistant cells (Figure 7E and 7F, Supplementary Figure 2D and 2E). The IF and IB results revealed that treatment with xanthohumol facilitated irradiation-induced DNA damage, as the population of $\mathrm{Y}-\mathrm{H} 2 \mathrm{AX}$ positive cells was increased substantially (Figure $7 \mathrm{G}$ and $7 \mathrm{H}$ ). In addition, combination of xanthohumol with irradiation promoted apoptosis in CAL27-IR cells (Figure 7I). To test whether xanthohumol overcomes radioresistance of OSCC cells in vivo, the CAL27 and CAL27-IR 
xenografts were treated with irradiation, xanthohumol, or in combination for 2 weeks. Xenografts derived from CAL27 cells were sensitive to irradiation with significant tumor shrinkage. In contrast, CAL27-IR xenografts were resistant to radiotherapy (Figure 7J and 7K). Strikingly, xanthohumol delayed the tumor development in both CAL27 and CAL27-IR derived xenografts, and the combination of xanthohumol sensitized CAL27-IR xenograft to radiotherapy (Figure 7J and 7K), indicating that xanthohumol is able to overcome radioresistance of OSCC cells in vivo. These results indicate that xanthohumol suppressed tumor growth and exhibited the potential to overcome radioresistance through in combination.

\section{Discussion}

As the smallest member of the IAP family protein, survivin is frequently overexpressed in human cancers, including lung (24), prostate (25), colorectal (25), breast (26), ovarian (27), and liver (28) cancer. Previous studies have revealed that beyond regulation of cell division and mitosis, overexpression of survivin in cancer cells inhibits both extrinsic and intrinsic apoptosis signaling. Even the underlying mechanisms of survivin-mediated apoptosis suppression remains unclear, the interaction between survivin and the initiator or effector caspases directly or indirectly is considered to contribute to this process (10). Importantly, the $\mathrm{C}$-terminus of survivin is dispensable for cell division, whereas the $\mathrm{N}$-terminus is required for apoptosis (29). Moreover, a high level of survivin is related to enhanced angiogenesis, tumor invasion and metastasis, and chemo/radioresistance, and downregulation of survivin reversed these functions (25, $30,31)$. For example, overexpression of survivin confers insulin-like growth factor-induced lapatinib resistance in head and neck squamous carcinoma cells (HNSCC) (32). Knockdown of survivin or inhibits survivin by inhibitors suppressed metastasis of ovarian cancer (27). Furthermore, reduction of survivin expression by Brexpiprazole sensitizes glioma cells to osimertinib treatment (33). In addition, suppression of survivin promotes the tumor-killing effect of radiotherapy in prostate cancer (34) and head and neck squamous cell carcinoma (HNSCC) $(35,36)$. In the present study, we found that survivin is highly expressed in OSCC tumor tissues and cells, depletion of survivin expression by sgRNA blunted the malignant phenotypes in OSCC cells, including in vitro cell proliferation, colony formation, and in vivo tumor development. This evidence indicates that survivin is a promising target for OSCC clinical treatment in the future.

The expression of survivin in human cancer cells is tightly controlled in multiple levels, including transcription, translation, and posttranslational modification (10). A panel of prooncogenic transcription factors, such as Sp1, NF-kB, STAT3, E2F1, and KLF5, have been demonstrated to bind with survivin promoter and enhanced survivin expression in various tumors, whereas p53, forkhead box 03 (FOXO3), and early growth response 1 transcription factor (Egr-1) is serving as negative regulators of survivin (10, 37). Beyond transcriptional and translational regulation, recent reports revealed that survivin undergoes various posttranslational modifications, including phosphorylation, acetylation, and ubiquitination. Phosphorylation is required for survivin stabilization, subcellular trafficking, and biological activation. Several protein kinases have been demonstrated to phosphorylate survivin on multiple sites, such as Aurora-B kinase, polo-like kinase (Plk1), protein kinase A (PKA), cyclin-dependent kinase 1 (Cdk1), and casein kinase II (CKII) (10). Phosphorylation on Thr34 is required for prevention of ubiquitination-induced 
survivin destruction (38). Our data showed that the natural compound, xanthohumol, inhibited survivin Thr34 phosphorylation in an Akt-Weel-CDK1 signaling dependent manner. Mutation of Thr34 to Ala promoted surviving ubiquitination and reduced protein half-life, which may contribute to xanthohumolmediated anti-tumor activity in vitro and in vivo.

Recent studies showed that the ubiquitin-proteasome pathway induces survivin degradation in a cell cycle-dependent manner (10). So far, two E3 ligases, X-linked inhibitor of apoptosis (XIAP) and F-box Protein FbxI7, have been identified to play key roles in the regulation of survivin stability. XIAP interacts with X-linked inhibitor of apoptosis (XIAP)-associated factor 1 (XAF1) and activates its E3 ligase activity to catalyze survivin ubiquitination and facilitates apoptosis (39). Fbxl7 directly induces survivin ubiquitylation and degradation to orchestrate mitochondria function (22). Furthermore, Aurora-A kinase promotes survivin stability through transcriptional and translational regulates of Fbxl7 expression in gastric cancer (40). Exception of lysine-48 mediated survivin ubiquitination is required for degradation, lysine-63 linked polyubiquitination chains regulate chromosome alignment and segregation in mitosis. Lys-63 de-ubiquitination of survivin by hFAM is required for the dissociation of survivin from centromeres. In contrast, ubiquitin-binding protein Ufd1 promoted Lys-63 ubiquitination is required for the association of survivin with centromeres (41). Importantly, the deubiquitinase, such as CSN5/Jab1, which removes the K-48 linked ubiquitination chains from survivin, stabilized survivin and promotes non-small cell lung cancer cell growth (42). Likewise, the ubiquitin-like protein FAT10 promotes bladder cancer progression by deubiquitination and stabilization of surviving (43). Our data showed that the natural compound, xanthohumol, reduced survivin protein level by enhancing Fbxl7-mediated ubiquitination and degradation. Xanthohumol promoted the interaction between Fbxl7 and survivin, which in turn facilitated Fbxl7-mediated survivin destruction and decreased survivin expression in OSCC cells. This mechanism is different from the current survivin suppressant YM155. YM155 robustly inhibits survivin activity via disruption of Sp1-DNA interaction in the survivin core promoter, thus inhibits survivin transcription (44), whereas xanthohumol is a potential survivin inhibitor which regulates survivin expression through posttranslational modification.

Xanthohumol is one of the most abundant prenylated flavonoids in hops (Humulus lupulus L.). Pharmacology studies showed that xanthohumol exhibits multiple biological functions, including antiinflammatory, antioxidant, antibacterial, and antiviral activity (45). Recently, accumulating evidence indicates that xanthohumol possesses the potent anti-cancer efficacy in various tumor models, such as hepatocellular carcinoma, leukemia, melanoma, non-small cell lung cancer, colorectal, ovarian, pancreatic, and cervical cancer (46). Mechanism study revealed that induction of cell cycle arrest, inhibition of glycolysis, promotion of DNA damage and apoptosis, and suppression of angiogenesis/metastasis are contributed to the anti-tumor activity of xanthohumol (46-48). Beyond that, the combination of xanthohumol with other therapeutic agents enhanced the tumor-killing effect of chemotherapy in various tumor models (49-51). In this study, we unexpectedly discovered that xanthohumol promoted survivin ubiquitination and degradation, which is required for xanthohumolmediated tumor suppression in OSCC cells. Importantly, in combination with radiation, xanthohumol 
overcomes radioresistance in OSCC xenograft tumors. These findings extend our understanding of the anti-tumor mechanisms of xanthohumol and offer a novel alternative opportunity for cancer treatment.

\section{Conclusion}

In summary, we identify that xanthohumol inhibits survivin phosphorylation by deregulation of Akt-Wee1CDK1 signaling and eventually promotes survivin ubiquitination and destruction by E3 ligase FbxI7. Thus, target oncoprotein for degradation might be a promising strategy for anti-tumor therapy.

\section{Abbreviations}

OSCC: oral squamous cell carcinoma, XN: xanthohumol, CPC: chromosomal passenger complex; IAPs: inhibitor of apoptosis protein family; HNSCC: head and neck squamous cell carcinoma; FOXO3: forkhead box 03; Egr-1: early growth response 1 transcription factor; PIk1: polo-like kinase; PKA: protein kinase A; Cdk1: cyclin-dependent kinase 1; CKII: casein kinase II; XIAP: X-linked inhibitor of apoptosis; XAF1: Xlinked inhibitor of apoptosis (XIAP)-associated factor 1; IB: Immunoblotting; IHC: Immunohistochemical staining; $\mathrm{CHX}$ : cycloheximide; Cyto: cytoplasmic fraction; Mito: Mitochondrial fraction; RBC: red blood cells; WBC: white blood cells; Hb: hemoglobin; ALT: alanine aminotransferase; AST: aspartate aminotransferase; BUN: blood urea nitrogen.

\section{Declarations}

\section{Ethics approval and consent to participate}

The animal experiments were approved by the Medical Research Animal Ethics Committee, Central South University, China.

\section{Consent for publication}

Not applicable.

\section{Availability of data and materials}

Materials are available upon request.

Competing interests: The authors have declared no conflicts of interest.

Funding: This work was supported by the National Natural Science Foundation of China (No.81904262, and No.81972837) and the Natural Science Foundation of Hunan Province (2018JJ3787, 2018JJ2604, 2019JJ50682).

Author's contributions: Conception and design: F. Gao, W. Li, X.-F Yu, M. Li.; Development of methodology: F. Gao, W. Li, L. Zhou, M. Li.; Acquisition of data: F. Gao, W. Li, Q. Zhao, L. Zhou, M. Li, W.-B Liu.; Analysis 
and interpretation of data: F. Gao, W. Li, Q. Zhao, L. Zhou, M. Li.; Writing, review, and/or revision of the manuscript: F. Gao, W. Li, X.-F Yu, M. Li.; Administrative, technical, or material support: F. Gao, X.-F Yu, W. Li, M. Li.; Study supervision: F. Gao, M. Li, X.-F Yu, W. Li.

\section{Acknowledgements}

We would like to thank Shiming Tan at the Third Xiangya Hospital for technical assistance.

\section{References}

1. Chai AWY, Lim KP, Cheong SC. Translational genomics and recent advances in oral squamous cell carcinoma. Semin Cancer Biol. 2019.

2. Yao C, Chang El, Lai SY. Contemporary Approach to Locally Advanced Oral Cavity Squamous Cell Carcinoma. Curr Oncol Rep. 2019;21(11):99.

3. Kim D, Li R. Contemporary Treatment of Locally Advanced Oral Cancer. Curr Treat Options Oncol. 2019;20(4):32.

4. Li CC, Shen Z, Bavarian R, Yang F, Bhattacharya A. Oral Cancer: Genetics and the Role of Precision Medicine. Surg Oncol Clin N Am. 2020;29(1):127-44.

5. Ghantous Y, Schussel JL, Brait M. Tobacco and alcohol-induced epigenetic changes in oral carcinoma. Curr Opin Oncol. 2018;30(3):152-8.

6. Gharat SA, Momin M, Bhavsar C. Oral Squamous Cell Carcinoma: Current Treatment Strategies and Nanotechnology-Based Approaches for Prevention and Therapy. Crit Rev Ther Drug Carrier Syst. 2016;33(4):363-400.

7. D'Souza S, Addepalli V. Preventive measures in oral cancer: An overview. Biomed Pharmacother. 2018;107:72-80.

8. Khan T, Relitti N, Brindisi M, Magnano S, Zisterer D, Gemma S, et al. Autophagy modulators for the treatment of oral and esophageal squamous cell carcinomas. Med Res Rev. 2019.

9. Lauritano D, Lucchese A, Contaldo M, Serpico R, Lo Muzio L, Biolcati F, et al. Oral squamous cell carcinoma: diagnostic markers and prognostic indicators. J Biol Regul Homeost Agents. 2016;30(2 Suppl 1):169-76.

10. Wheatley SP, Altieri DC. Survivin at a glance. J Cell Sci. 2019;132(7).

11. Mobahat M, Narendran A, Riabowol K. Survivin as a preferential target for cancer therapy. Int J Mol Sci. 2014;15(2):2494-516.

12. Cheung $\mathrm{CH}$, Huang CC, Tsai FY, Lee JY, Cheng SM, Chang YC, et al. Survivin - biology and potential as a therapeutic target in oncology. Onco Targets Ther. 2013;6:1453-62.

13. Huang YH, Yeh CT. Functional Compartmentalization of HSP60-Survivin Interaction between Mitochondria and Cytosol in Cancer Cells. Cells. 2019;9(1).

14. Frassanito MA, Saltarella I, Vinella A, Muzio LL, Pannone G, Fumarulo R, et al. Survivin overexpression in head and neck squamous cell carcinomas as a new therapeutic target (Review). 
Oncol Rep. 2019;41(5):2615-24.

15. Rafatmanesh A, Behjati M, Mobasseri N, Sarvizadeh M, Mazoochi T, Karimian M. The survivin molecule as a double-edged sword in cellular physiologic and pathologic conditions and its role as a potential biomarker and therapeutic target in cancer. J Cell Physiol. 2020;235(2):725-44.

16. Buscheck F, Sulimankhil M, Melling N, Hoflmayer D, Hube-Magg C, Simon R, et al. Loss of cytoplasmic survivin expression is an independent predictor of poor prognosis in radically operated prostate cancer patients. Cancer Med. 2020.

17. Li W, Yu X, Xia Z, Yu X, Xie L, Ma X, et al. Repression of Noxa by Bmi1 contributes to deguelin-induced apoptosis in non-small cell lung cancer cells. J Cell Mol Med. 2018;22(12):6213-27.

18. Yu X, Li W, Xia Z, Xie L, Ma X, Liang Q, et al. Targeting MCL-1 sensitizes human esophageal squamous cell carcinoma cells to cisplatin-induced apoptosis. BMC Cancer. 2017;17(1):449.

19. Yu X, Liang Q, Liu W, Zhou L, Li W, Liu H. Deguelin, an Aurora B Kinase Inhibitor, Exhibits Potent AntiTumor Effect in Human Esophageal Squamous Cell Carcinoma. EBioMedicine. 2017;26:100-11.

20. Li W, Yu X, Ma X, Xie L, Xia Z, Liu L, et al. Deguelin attenuates non-small cell lung cancer cell metastasis through inhibiting the CtsZ/FAK signaling pathway. Cell Signal. 2018;50:131-41.

21. Yu X, Wang R, Zhang Y, Zhou L, Wang W, Liu H, et al. Skp2-mediated ubiquitination and mitochondrial localization of Akt drive tumor growth and chemoresistance to cisplatin. Oncogene. 2019;38(50):7457-72.

22. Liu Y, Lear T, Iannone O, Shiva S, Corey C, Rajbhandari S, et al. The Proapoptotic F-box Protein FbxI7 Regulates Mitochondrial Function by Mediating the Ubiquitylation and Proteasomal Degradation of Survivin. J Biol Chem. 2015;290(19):11843-52.

23. Katayama K, Fujita N, Tsuruo T. Akt/protein kinase B-dependent phosphorylation and inactivation of WEE1Hu promote cell cycle progression at G2/M transition. Mol Cell Biol. 2005;25(13):5725-37.

24. Nitschkowski D, Marwitz S, Kotanidou SA, Reck M, Kugler C, Rabe KF, et al. Live and let die: epigenetic modifications of Survivin and Regucalcin in non-small cell lung cancer tissues contribute to malignancy. Clin Epigenetics. 2019;11(1):157.

25. Yang F, Ma J, Wan J, Ha W, Fang C, Lu H, et al. Epithelial-mesenchymal transition of circulating tumor cells in prostate cancer is promoted by survivin. J Int Med Res. 2020;48(1):300060519892395.

26. Neophytou CM, Mesaritis A, Gregoriou G, Constantinou Al. d-a-Tocopheryl Polyethylene Glycol 1000 Succinate and a small-molecule Survivin suppressant synergistically induce apoptosis in SKBR3 breast cancer cells. Sci Rep. 2019;9(1):14375.

27. Zhao G, Wang Q, Wu Z, Tian X, Yan H, Wang B, et al. Ovarian Primary and Metastatic Tumors Suppressed by Survivin Knockout or a Novel Survivin Inhibitor. Mol Cancer Ther. 2019;18(12):223345.

28. Kapiris I, Nastos K, Karakatsanis A, Theodosopoulos T, Karandrea D, Kondi Pafiti A, et al. Survivin expression in hepatocellular carcinoma. Correlation with clinicopathological characteristics and overall survival. J BUON. 2019;24(5):1934-42. 
29. Wheatley SP. The functional repertoire of survivin's tails. Cell Cycle. 2015;14(2):261-8.

30. Sanhueza C, Wehinger S, Castillo Bennett J, Valenzuela M, Owen GI, Quest AF. The twisted survivin connection to angiogenesis. Mol Cancer. 2015;14:198.

31. Martinez-Garcia D, Manero-Ruperez N, Quesada R, Korrodi-Gregorio L, Soto-Cerrato V. Therapeutic strategies involving survivin inhibition in cancer. Med Res Rev. 2019;39(3):887-909.

32. Lehman CE, Mendez RE, Dougherty MI, Allak A, Adejumo OL, Taniguchi LE, et al. Survivin in InsulinLike Growth Factor-Induced Resistance to Lapatinib in Head and Neck Squamous Carcinoma Cells. Front Oncol. 2019;9:13.

33. Suzuki S, Yamamoto M, Sanomachi T, Togashi K, Sugai A, Seino S, et al. Brexpiprazole, a SerotoninDopamine Activity Modulator, Can Sensitize Glioma Stem Cells to Osimertinib, a Third-Generation EGFR-TKI, via Survivin Reduction. Cancers (Basel). 2019;11(7).

34. Wang T, Huang J, Vue M, Alavian MR, Goel HL, Altieri DC, et al. alphavbeta3 Integrin Mediates Radioresistance of Prostate Cancer Cells through Regulation of Survivin. Mol Cancer Res. 2019;17(2):398-408.

35. Wang X, Beitler JJ, Huang W, Chen G, Qian G, Magliocca K, et al. Honokiol Radiosensitizes Squamous Cell Carcinoma of the Head and Neck by Downregulation of Survivin. Clin Cancer Res. 2018;24(4):858-69.

36. Khan Z, Khan AA, Prasad GB, Khan N, Tiwari RP, Bisen PS. Growth inhibition and chemoradiosensitization of head and neck squamous cell carcinoma (HNSCC) by survivin-siRNA lentivirus. Radiother Oncol. 2016;118(2):359-68.

37. Boidot R, Vegran F, Lizard-Nacol S. Transcriptional regulation of the survivin gene. Mol Biol Rep. 2014;41(1):233-40.

38. Aspe JR, Wall NR. Survivin-T34A: molecular mechanism and therapeutic potential. Onco Targets Ther. 2010;3:247-54.

39. Arora V, Cheung HH, Plenchette S, Micali OC, Liston P, Korneluk RG. Degradation of survivin by the Xlinked inhibitor of apoptosis (XIAP)-XAF1 complex. J Biol Chem. 2007;282(36):26202-9.

40. Kamran M, Long ZJ, Xu D, Lv SS, Liu B, Wang CL, et al. Aurora kinase A regulates Survivin stability through targeting FBXL7 in gastric cancer drug resistance and prognosis. Oncogenesis. 2017;6(2):e298.

41. Vong QP, Cao K, Li HY, Iglesias PA, Zheng Y. Chromosome alignment and segregation regulated by ubiquitination of survivin. Science. 2005;310(5753):1499-504.

42. Li J, Li Y, Wang B, Ma Y, Chen P. CSN5/Jab1 facilitates non-small cell lung cancer cell growth through stabilizing survivin. Biochem Biophys Res Commun. 2018;500(2):132-8.

43. Dong D, Jiang W, Lei J, Chen L, Liu X, Ge J, et al. Ubiquitin-like protein FAT10 promotes bladder cancer progression by stabilizing survivin. Oncotarget. 2016;7(49):81463-73.

44. Nakahara T, Kita A, Yamanaka K, Mori M, Amino N, Takeuchi M, et al. YM155, a novel small-molecule survivin suppressant, induces regression of established human hormone-refractory prostate tumor 
xenografts. Cancer Res. 2007;67(17):8014-21.

45. Liu M, Hansen PE, Wang G, Qiu L, Dong J, Yin H, et al. Pharmacological profile of xanthohumol, a prenylated flavonoid from hops (Humulus lupulus). Molecules. 2015;20(1):754-79.

46. Jiang CH, Sun TL, Xiang DX, Wei SS, Li WQ. Anticancer Activity and Mechanism of Xanthohumol: A Prenylated Flavonoid From Hops (Humulus lupulus L.). Front Pharmacol. 2018;9:530.

47. Lin M, Xiang D, Chen X, Huo H. Role of Characteristic Components of Humulus lupulus in Promoting Human Health. J Agric Food Chem. 2019;67(30):8291-302.

48. Liu W, Li W, Liu H, Yu X. Xanthohumol inhibits colorectal cancer cells via downregulation of Hexokinases II-mediated glycolysis. Int J Biol Sci. 2019;15(11):2497-508.

49. Ambroz M, Lnenickova K, Matouskova P, Skalova L, Bousova I. Antiproliferative Effects of Hopderived Prenylflavonoids and Their Influence on the Efficacy of Oxaliplatine, 5-fluorouracil and Irinotecan in Human ColorectalC Cells. Nutrients. 2019;11(4).

50. Bartmanska A, Tronina T, Poplonski J, Milczarek M, Filip-Psurska B, Wietrzyk J. Highly Cancer Selective Antiproliferative Activity of Natural Prenylated Flavonoids. Molecules. 2018;23(11).

51. Tronina T, Bartmanska A, Filip-Psurska B, Wietrzyk J, Poplonski J, Huszcza E. Fungal metabolites of xanthohumol with potent antiproliferative activity on human cancer cell lines in vitro. Bioorg Med Chem. 2013;21(7):2001-6.

\section{Figures}


A

C

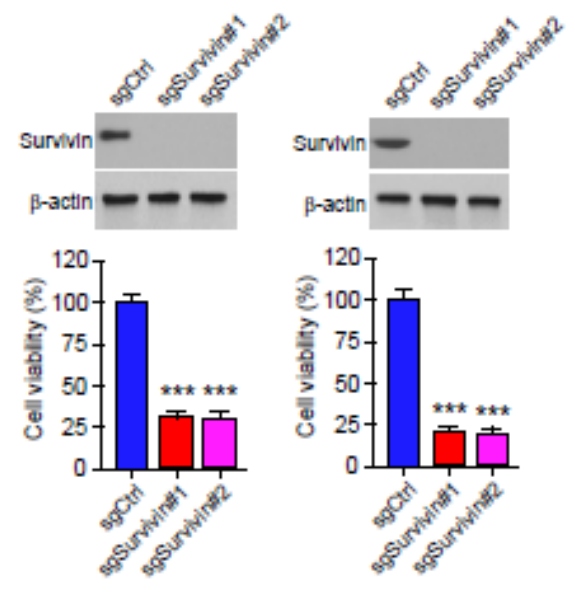

E

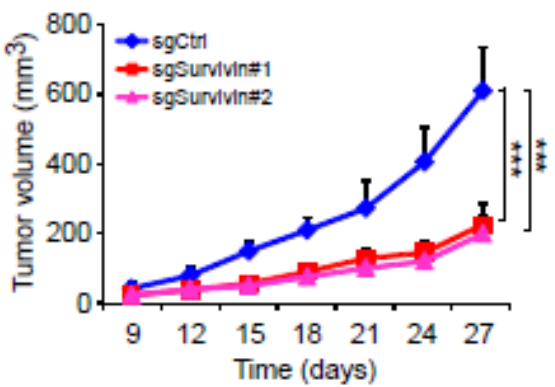

$\mathrm{H}$

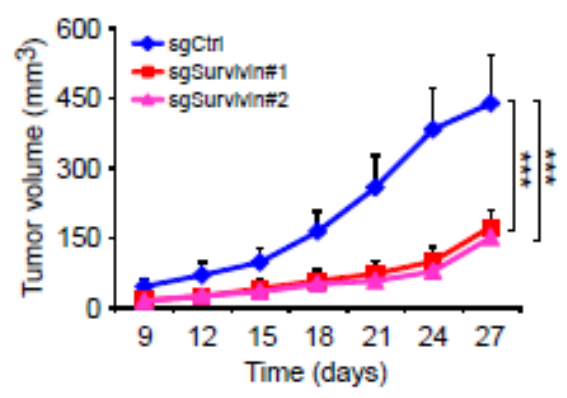

B
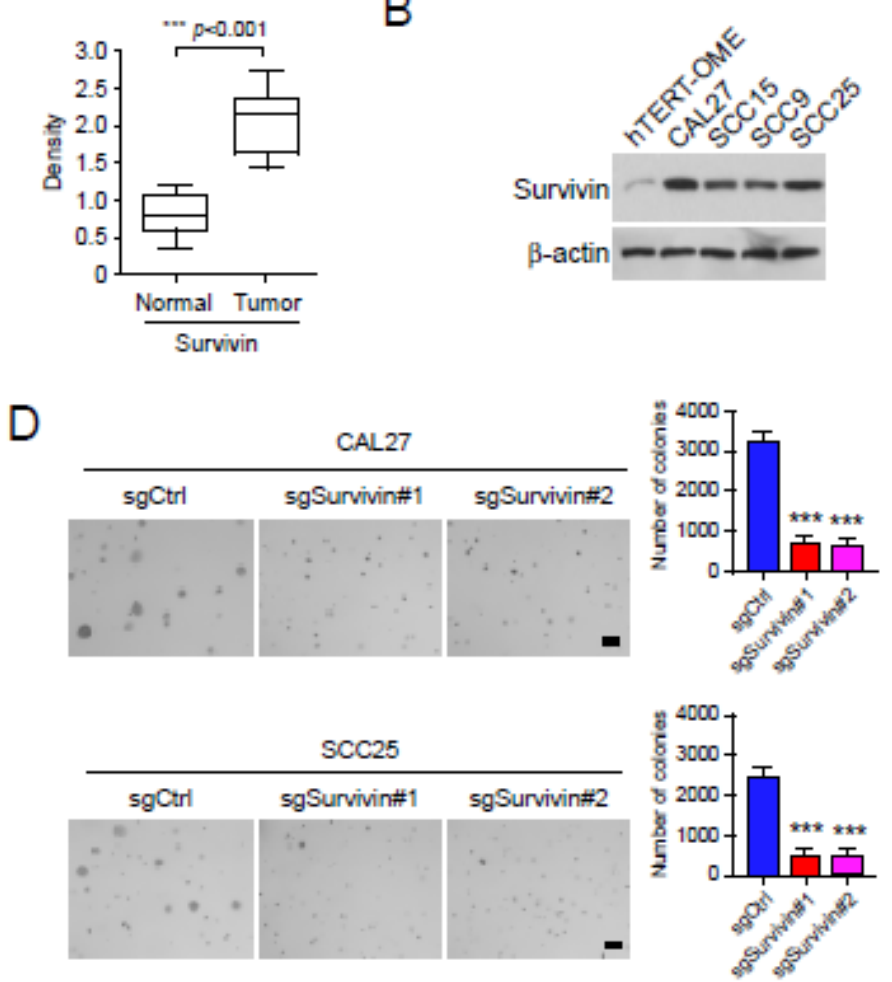

F

G
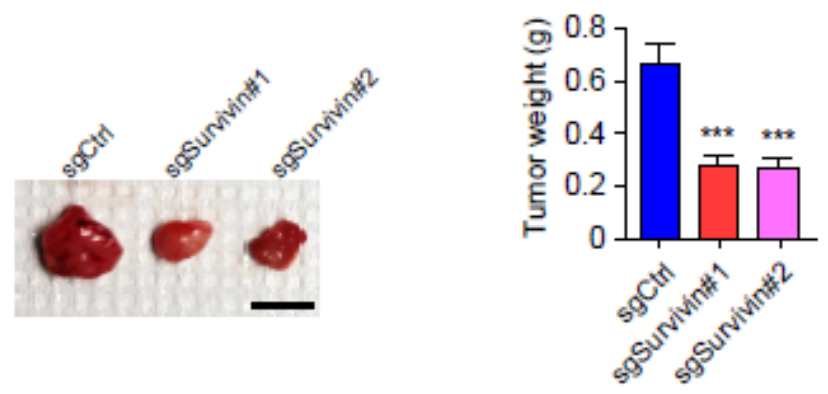

I

J

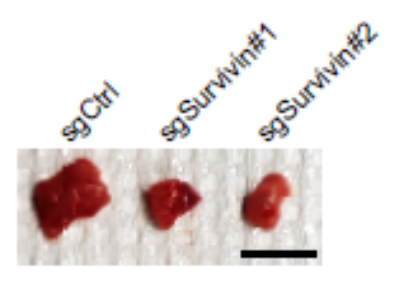

\section{Figure 1}

Overexpression of survivin is required for maintaining of tumorigenic properties of oral squamous cell carcinoma (OSCC) cells. A, Left, the expression of survivin in five representative OSCC tissues was examined by IB analysis. A total of 35 cases of paired OSCC tissue and adjacent non-tumor tissue were subjected to IB analysis. Right, relative survivin expression was determined by quantification analysis. $\mathrm{N}$, adjacent non-tumor tissue, T, tumor tissue. B, The expression of survivin in immortalized oral epithelial 
cell and OSCC cells. C, Knockout of survivin decreased cell viability in CAL27 (left) and SCC25 (right) cells. D, Knockout of survivin inhibited colony formation of CAL27 (top) and SCC25 (bottom) cells. Scale bar, $200 \mu \mathrm{m}$. E-G, The tumor volume (E), the image of tumor mass (F), and tumor weight (G) of CAL27derived xenograft tumors with survivin knockout or not. $\mathrm{H}-\mathrm{J}$, The tumor volume $(\mathrm{H})$, image of tumor mass $(\mathrm{I})$, and tumor weight $(\mathrm{J})$ of SCC25-derived xenograft tumors with survivin knockout or not. ${ }^{\star \star \star} \mathrm{p}<0.001$. For $\mathrm{F}$ and $\mathrm{I}$, Scale bar, $1 \mathrm{~cm}$.

A

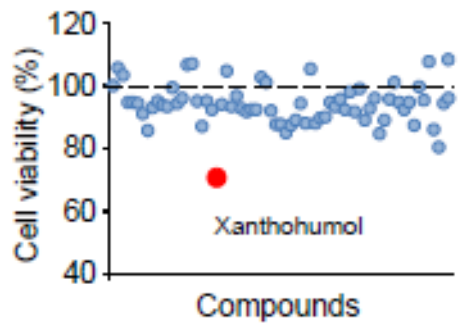

D

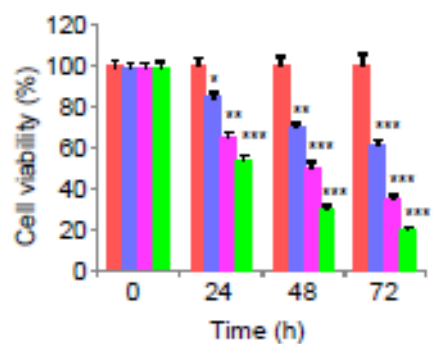

E
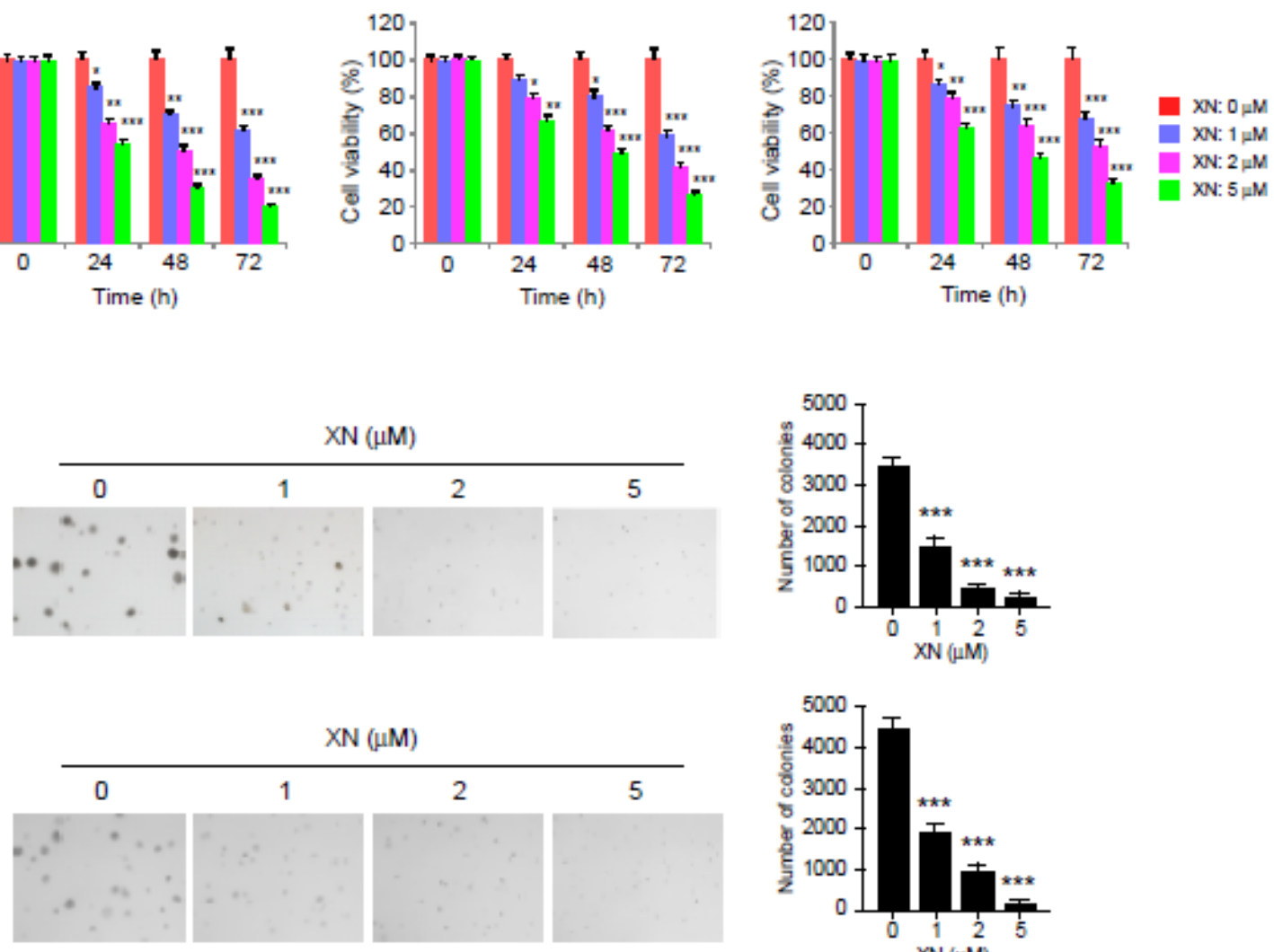

$\mathrm{XN}(\mu \mathrm{M})$

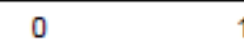

1

2

5
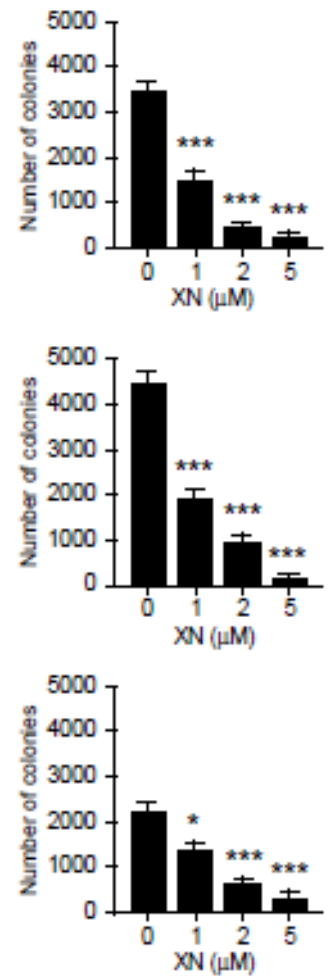

Figure 2 
Xanthohumol $(\mathrm{XN})$ suppresses OSCC cells. A, Xanthohumol is a candidate natural product which inhibits OSCC cell viability significantly. A total of 70 compounds $(1 \mu \mathrm{M})$ of interest were treated with CAL27 cells for $48 \mathrm{~h}$. Cell viability was examined by the MTS assay. B, The chemical structure of xanthohumol. C, MTS assay analysis of the effect of xanthohumol on immortalized HaCat cells. D, The effect of xanthohumol on cell viability of OSCC cells. SCC25 (left), SCC9 (middle), and CAL27 (right) cells were treated with xanthohumol or DMSO control. Cell viability was examined by the MTS assay. E, The effect of xanthohumol on colony formation of OSCC cells. SCC25 (left), SCC9 (middle), and CAL27 (right) cells were treated with xanthohumol or DMSO control, the colony formation efficacy of OSCC cells was determined by soft agar assay. XN, xanthohumol. ${ }^{*} p<0.05,{ }^{* *} p<0.01,{ }^{* *} \mathrm{p}<0.001$.

A

B
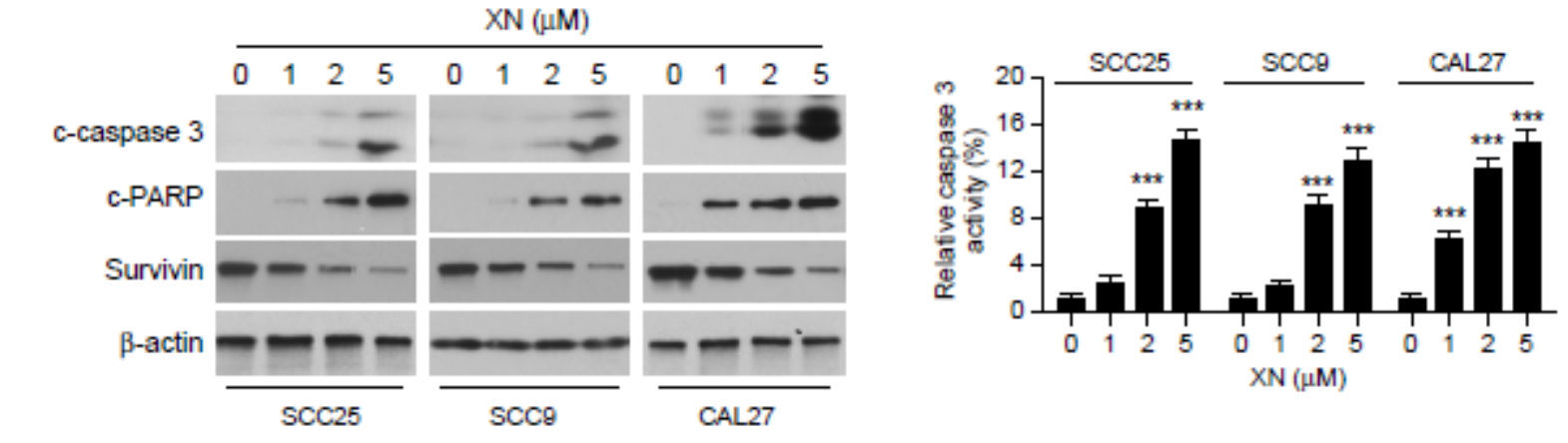

C
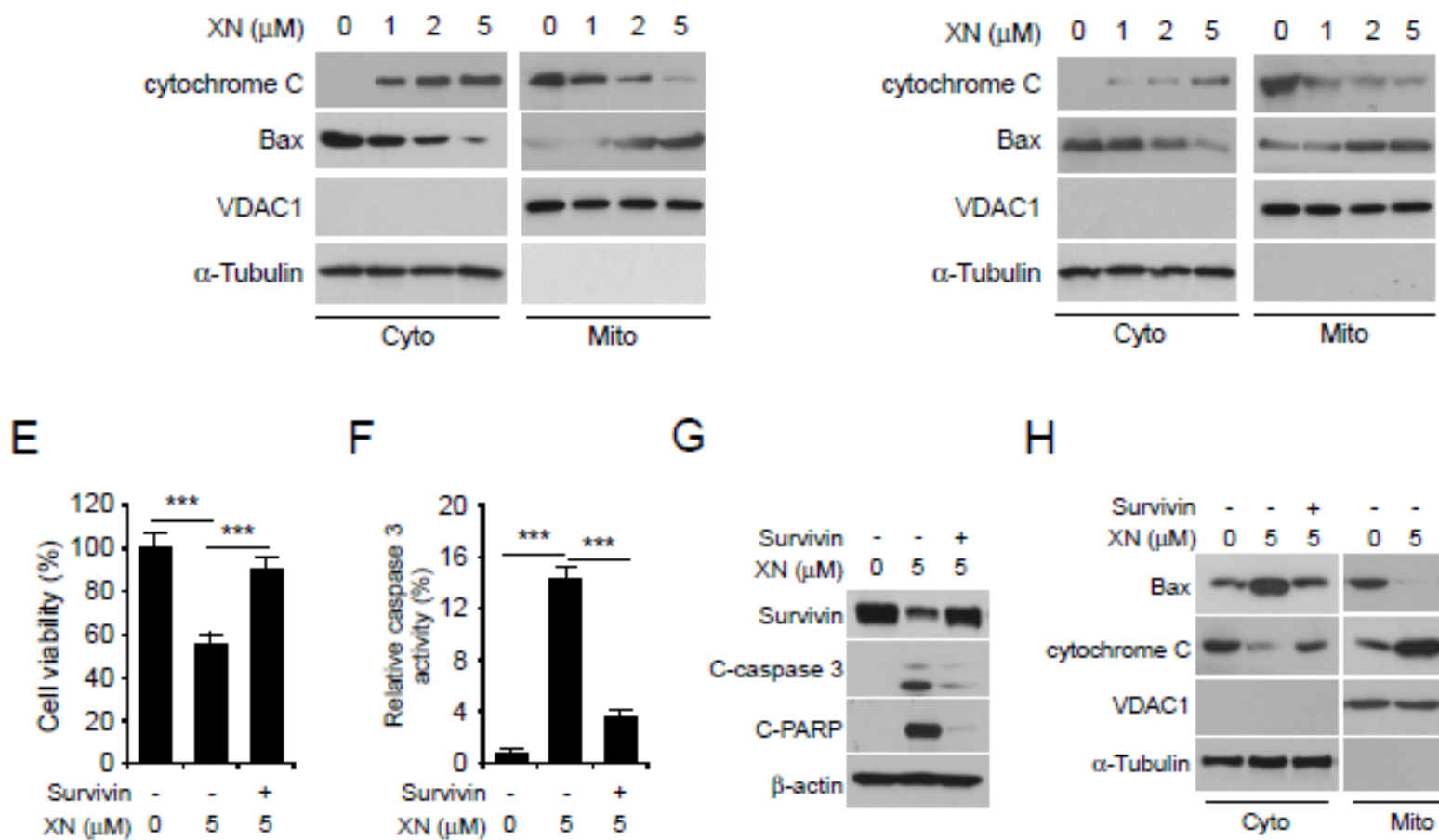

F

G

$\mathrm{H}$
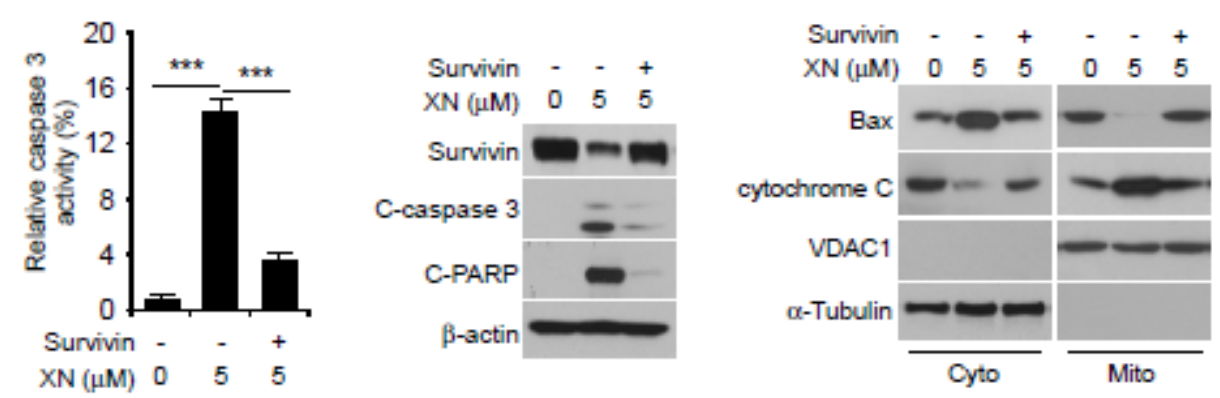

\section{Figure 3}

Xanthohumol causes mitochondrial apoptosis in OSCC cells through downregulating of survivin expression. A and B, OSCC cells were treated with xanthohumol for $24 \mathrm{~h}$, the whole-cell extract was 
subjected to IB analysis (A) and cleaved-caspase 3 activity measurement (B). C and D, SCC25 (C) and CAL27 (D) cells were treated with xanthohumol for $24 \mathrm{~h}$. Subcellular fractions were isolated and subjected to IB analysis. Cyto, cytosolic fraction; Mito, mitochondrial fraction. E, Ectopic overexpression of survivin rescued xanthohumol-induced cell viability reduction. SCC25 cells were transfected with survivin CDNA and treated with xanthohumol for 24 , cell viability was determined by MTS assay. F, SCC25 cells were treated as in "Figure 3E", whole-cell lysate was subjected to cleaved-caspase 3 activity analysis. G, SCC25 cells were treated as in "Figure 3E", whole-cell lysate was subjected to IB analysis. H, SCC25 cells were treated as in "Figure 3E", subcellular fractions were isolated and subjected to IB analysis. ${ }^{* \star *} p<0.001$. 
A

C

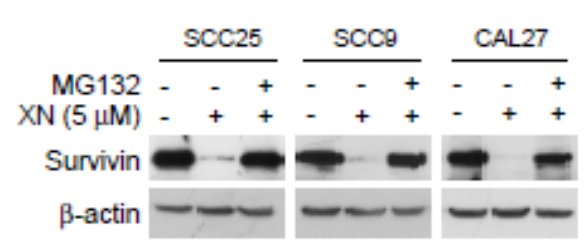

B

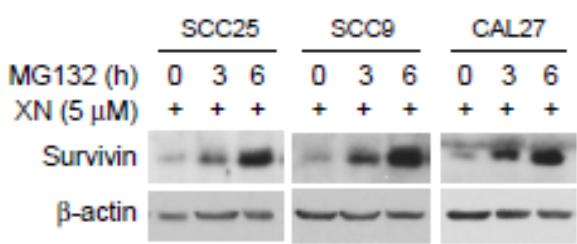

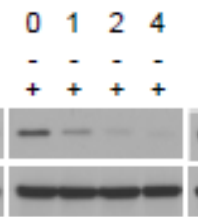

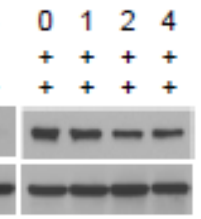

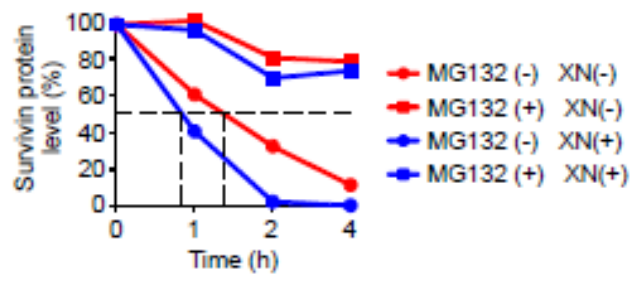

F
D

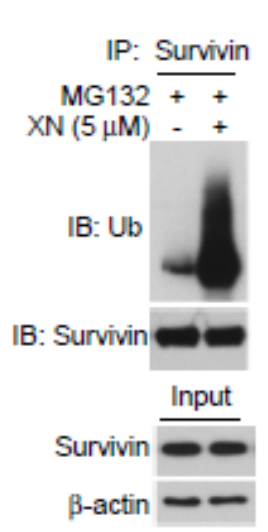

$\mathrm{H}$

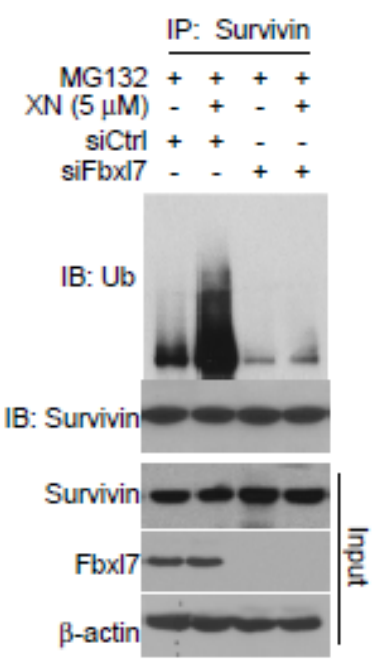

E

HA-Fbxl7 $(\mu \mathrm{g}) \quad 0 \quad 1 \quad 2 \quad 4$

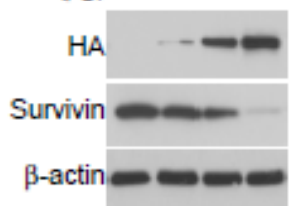

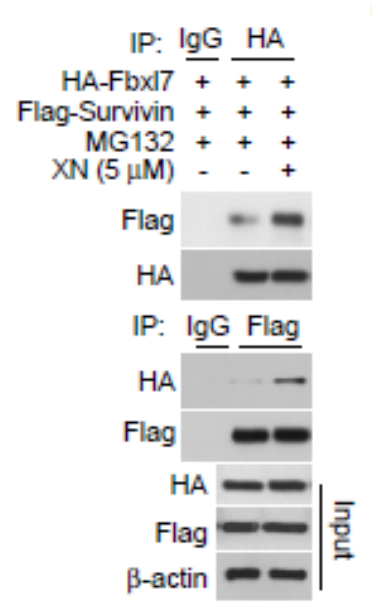

G

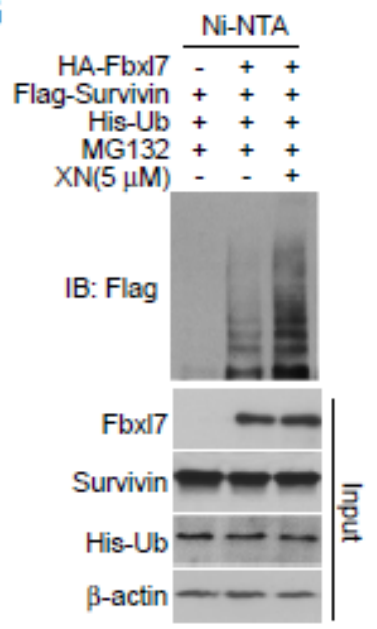

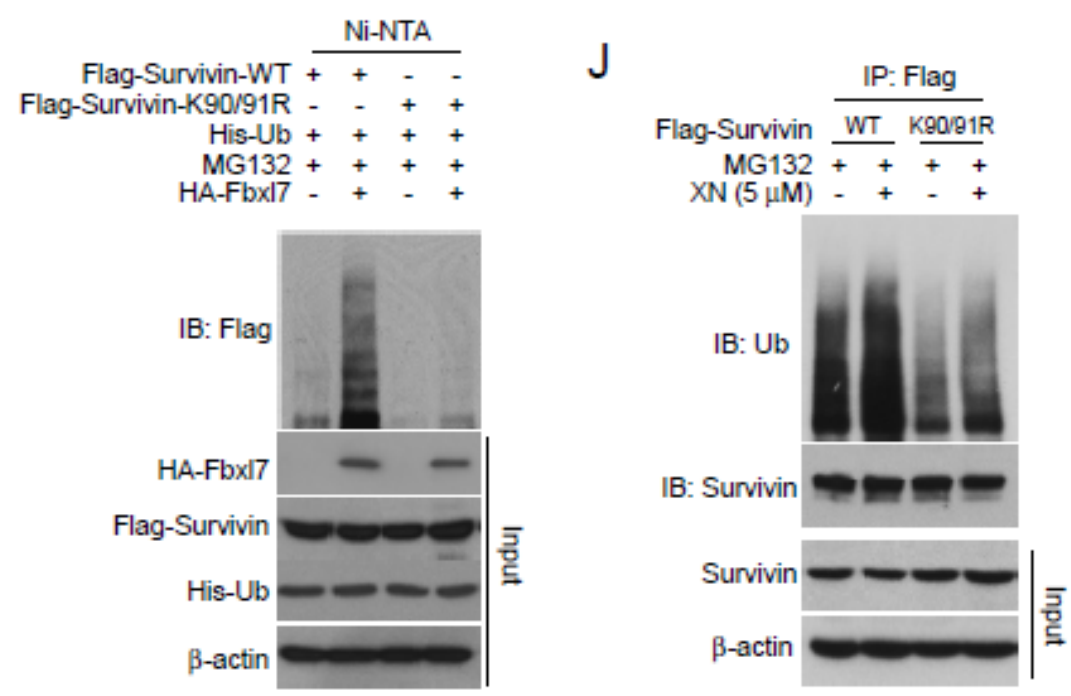

\section{Figure 4}

Xanthohumol promotes survivin ubiquitination and degradation in an Fbxl7-dependent manner. A, MG132 rescued xanthohumol-induced survivin downregulation. OSCC cells were treated with xanthohumol, followed by MG132 treated for $6 \mathrm{~h}$. The whole-cell extract was subjected to IB analysis. B, MG132 rescued xanthohumol-induced survivin downregulation time-dependently. OSCC cells were treated with xanthohumol, followed by MG132 treated for various time points, whole-cell extract was subjected to IB 
analysis. C, Xanthohumol shortened the half-life of survivin. SCC25 cells were treated with xanthohumol or DMSO control, followed by MG132 treated for $6 \mathrm{~h}$ or not, whole-cell extract was subjected to IB analysis. D, Xanthohumol promoted survivin ubiquitination. SCC25 cells were treated with xanthohumol and subjected to ubiquitination analysis. E, SCC25 cells were transfected with HA-Fbxl7 for $48 \mathrm{~h}$. Cell lysates were subjected to IB analysis. F, SCC25 cells were transfected with HA-Fbxl7 and Flag-Survivin plasmids as indicated, followed by xanthohumol treated for $24 \mathrm{~h}$, the whole-cell lysate was prepared and subjected to Co-IP and IB analysis. G, SCC25 cells were transfected with various plasmids as indicated, followed by xanthohumol treated for $24 \mathrm{~h}$, the whole-cell lysate was subjected to ubiquitination analysis. $\mathrm{H}, \mathrm{SCC} 25$ cells were transfected with various siRNA as indicated, followed by xanthohumol treated for 24 h, the whole-cell lysate was prepared and subjected to Co-IP and IB analysis. I, SCC25 cells were transfected with Flag-Survivin-WT or K90/91R mutant together with HA-Fbxl7 as indicated, followed by xanthohumol treated for $24 \mathrm{~h}$, the whole-cell lysate was prepared and subjected to ubiquitination analysis. J, SCC25 cells were transfected with Flag-Survivin-WT or K90/91R mutant and treated with xanthohumol for $24 \mathrm{~h}$. The whole-cell lysate was prepared and subjected to ubiquitination analysis. 
A
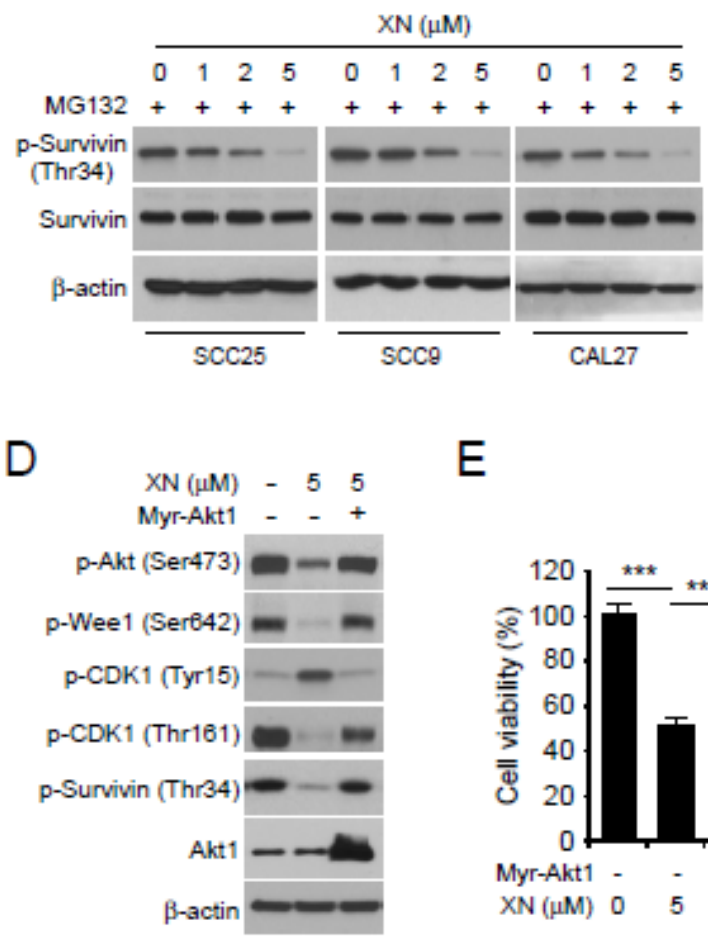

$\mathrm{H}$

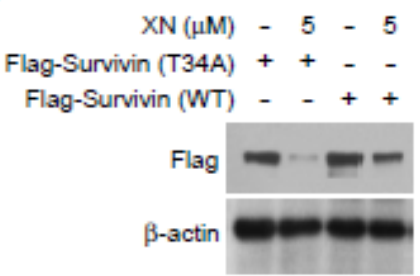

J

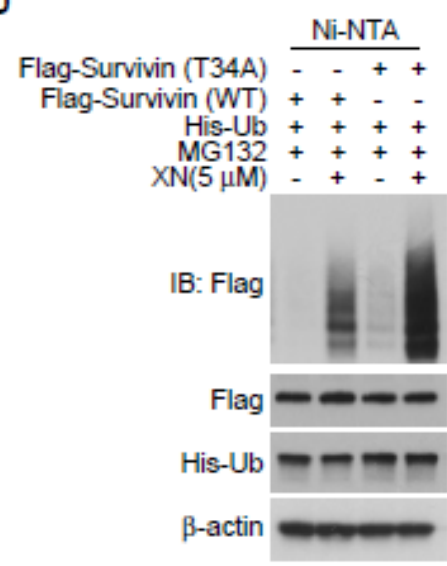

I

K
B

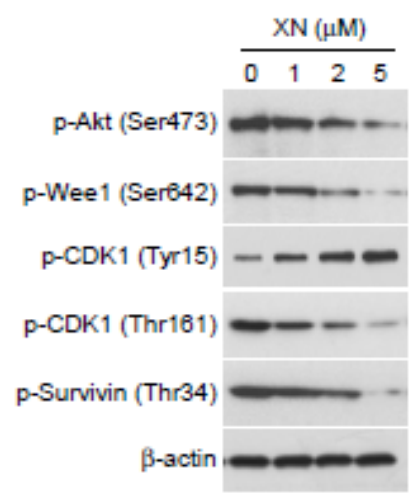

E

F

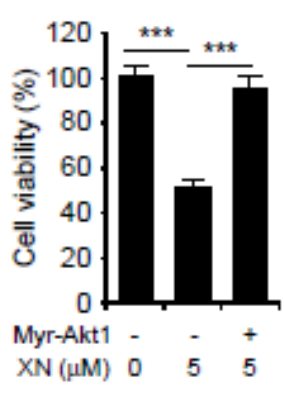

C

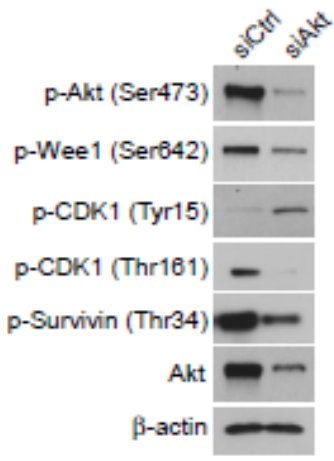

$G$

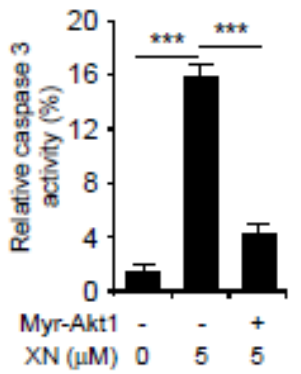

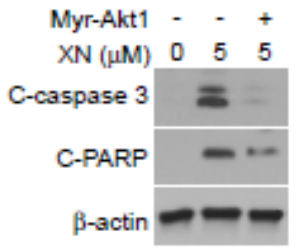
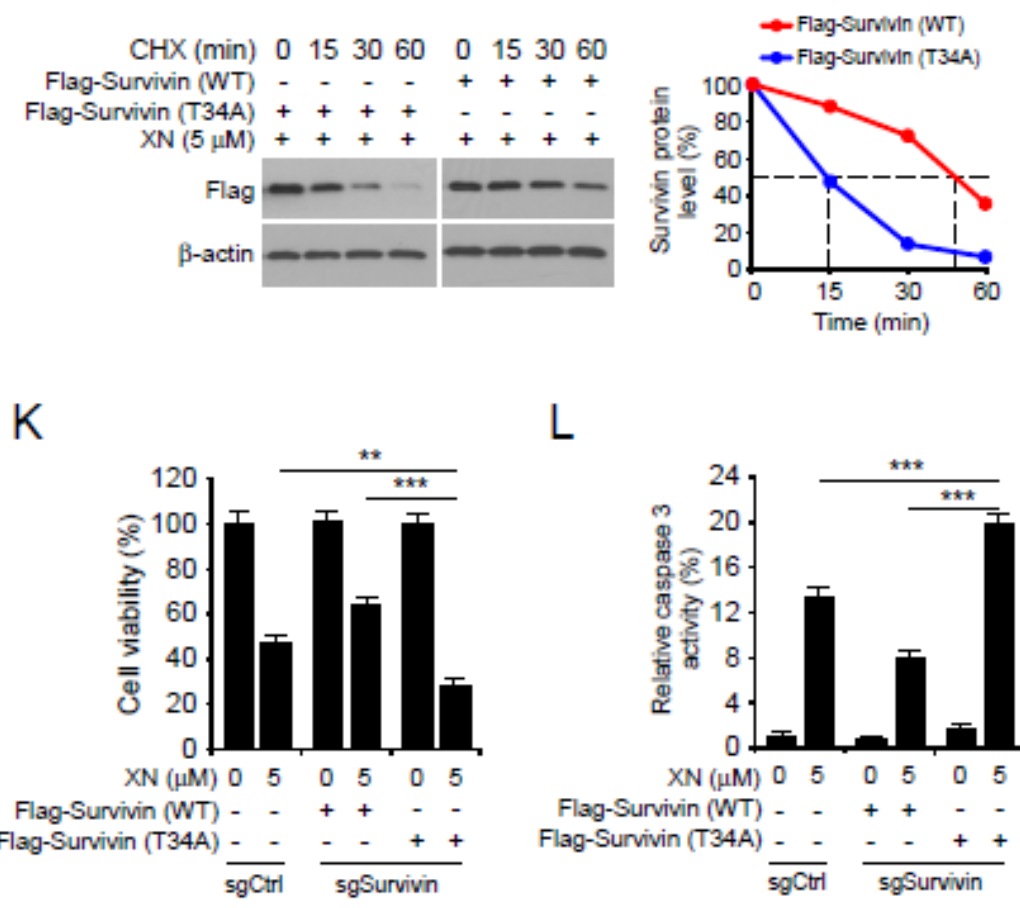

L

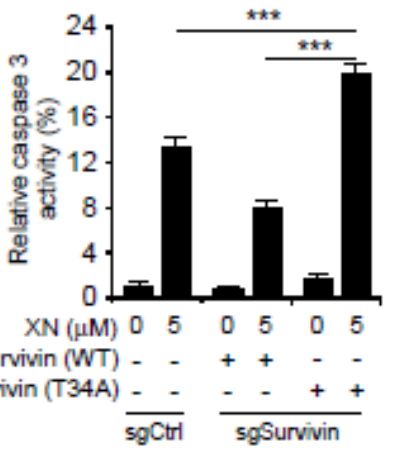

\section{Figure 5}

Xanthohumol-decreased survivin Thr34 phosphorylation is required for survivin ubiquitination. $A$ and $B$, OSCC cells were treated with xanthohumol for $24 \mathrm{~h}$, the whole-cell lysate was subjected to IB analysis. C, SCC25 cells were transfected with siCtrl or siAkt and treated with xanthohumol for $24 \mathrm{~h}$, and whole cell lysate was subjected to IB analysis. D, SCC25 cells were transfected with Mry-Akt1 and treated with xanthohumol for $24 \mathrm{~h}$, the whole-cell lysate was subjected to IB analysis. E-G, SCC25 cells were treated as 
in "Figure 5D", cells were subject to MTS assay (E), cleaved-caspase 3 activity analysis (F), and IB analysis (G). H, SCC25 cells were transfected with Flag-Survivin-WT or T34A and treated with xanthohumol for $24 \mathrm{~h}$, the whole-cell lysate was subjected to IB analysis. I, SCC25 cells were transfected with Flag-Survivin-WT or T34A and treated with xanthohumol for $24 \mathrm{~h}$. CHX was added into the cell culture medium for various time points. The whole-cell lysate was subjected to IB analysis. J, SCC25 cells were transfected with various plasmids and treated with xanthohumol for $24 \mathrm{~h}$. The whole-cell lysate was subjected to ubiquitination analysis. K and L, Survivin WT or knockout SCC25 cells were transfected with survivin WT or T34A mutant and treated with xanthohumol as indicated. Cells were subjected to MTS assay (K) and cleaved-caspase 3 activity analysis (L). ** $\mathrm{p}<0.001$.

A

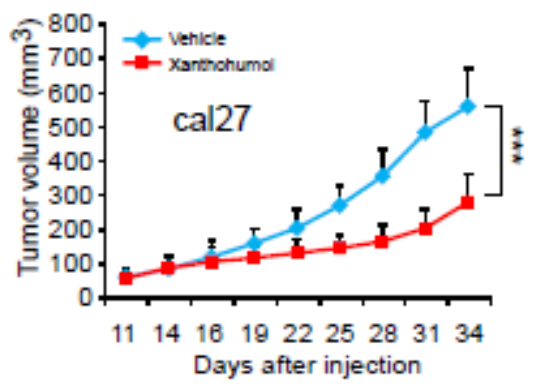

D

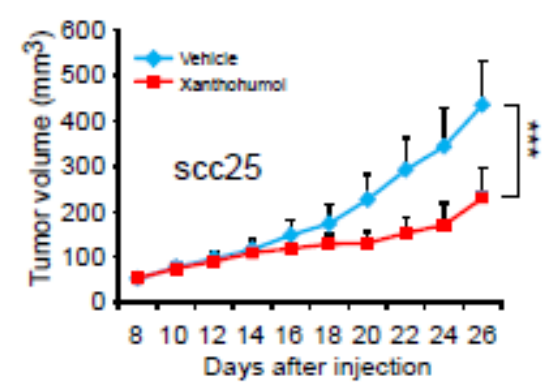

G

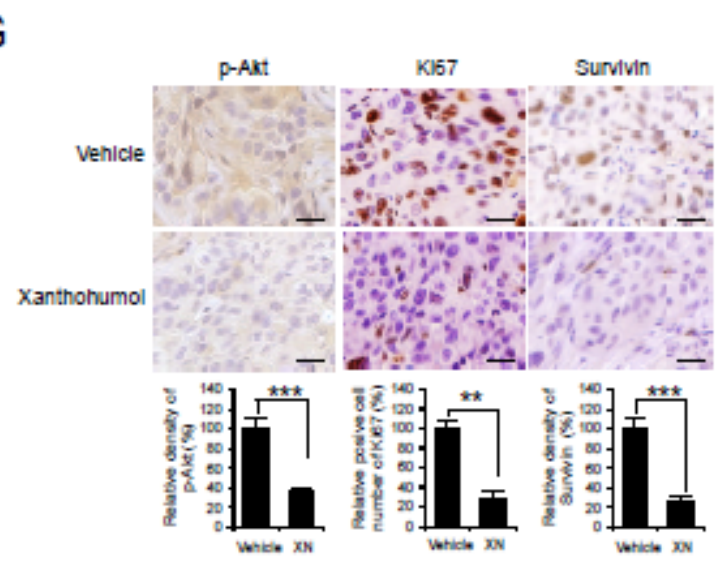

B

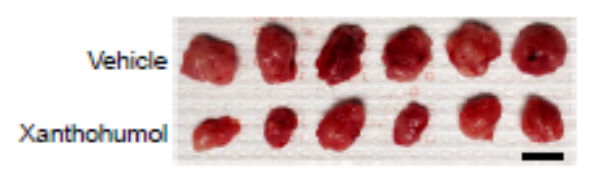

E

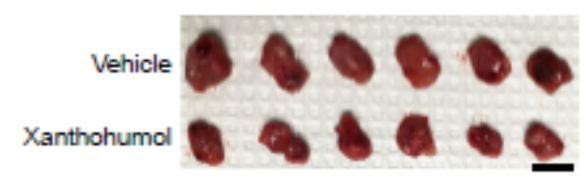

C

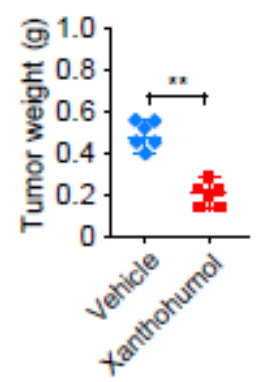

F

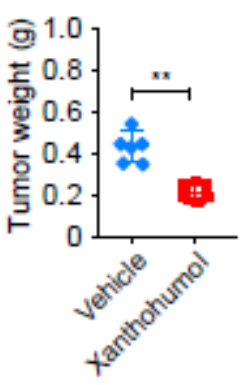

$\mathrm{H}$
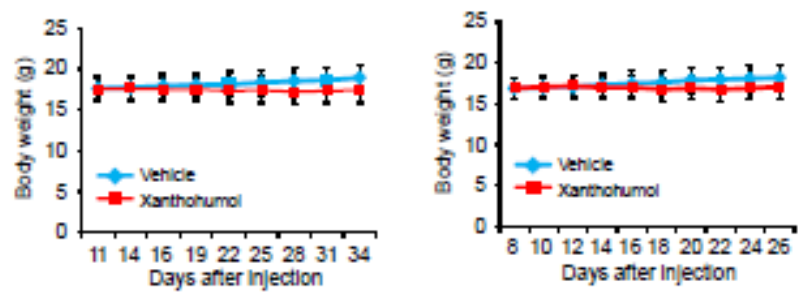

J
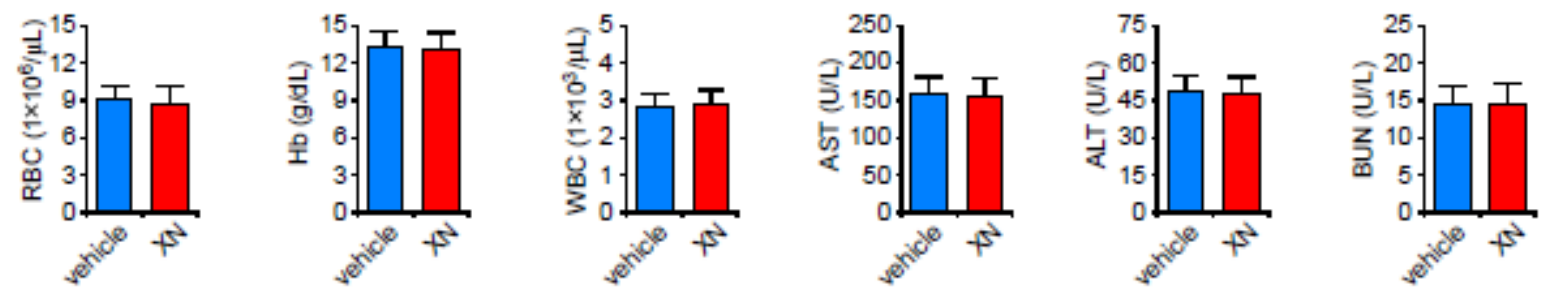


\section{Figure 6}

Xanthohumol suppresses in vivo xenograft tumor growth. A-C, Xanthohumol inhibited CAL27-derived xenograft tumor growth. The tumor volume (A), the image of tumor mass (B), and tumor weight $(C)$ of vehicle- and xanthohumol-treated tumors. D-F, Xanthohumol inhibited SCC25-derived xenograft tumor growth. The tumor volume (D), image of tumor mass $(E)$, and tumor weight $(F)$ of vehicle- and xanthohumol-treated tumors. G, IHC staining analysis of Ki67, p-Akt, and survivin in SCC25-derived xenograft tumors. $\mathrm{H}$ and I, The body weights of CAL27 (H) and SCC25 (I) tumor-bearing mice with vehicle or xanthohumol treatment. J, Blood analysis of mice with vehicle or xanthohumol treatment. ${ }^{* \star} p<0.01$, $\star \star \star p<0.001$. 
A

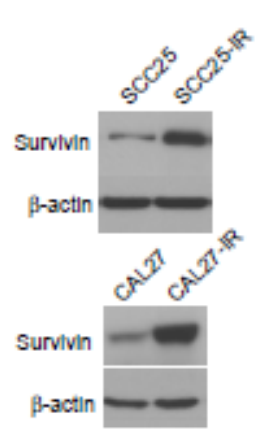

B

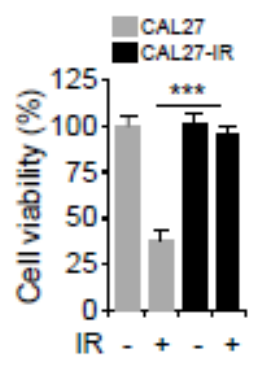

C

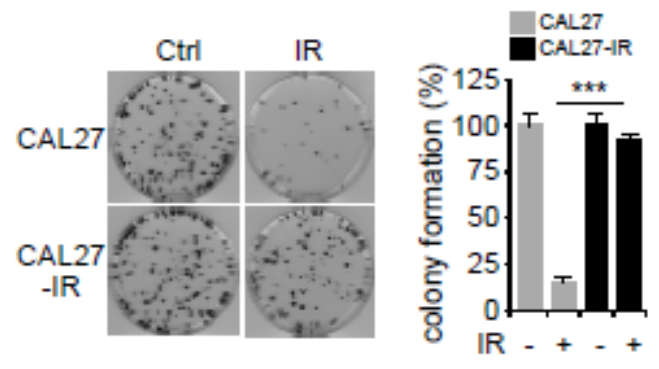

D

E

F
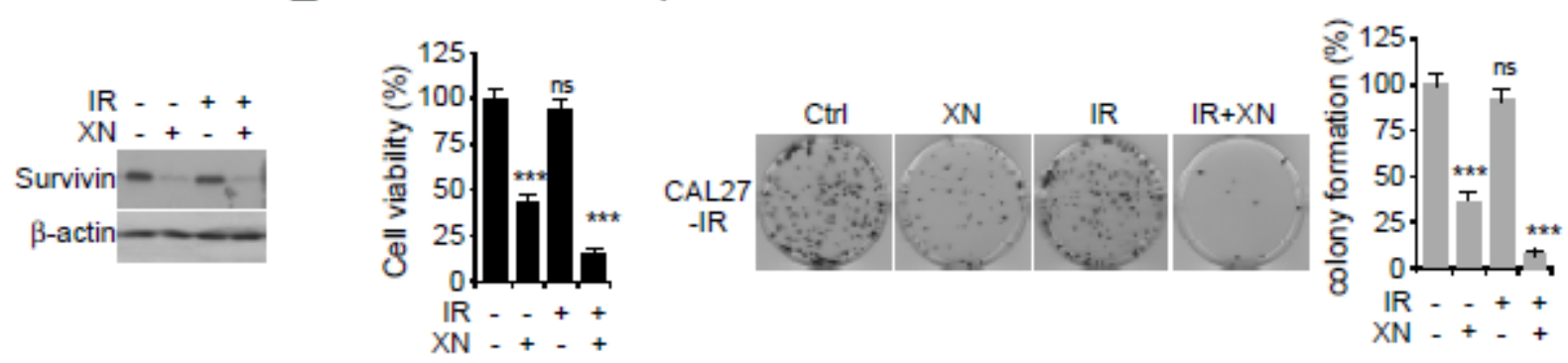

G
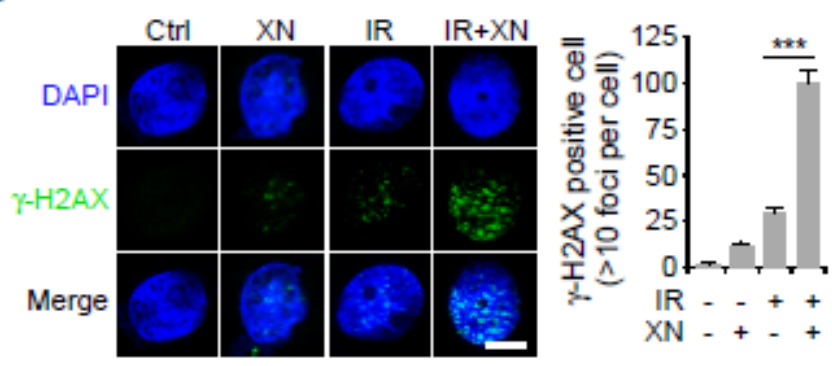

$\mathrm{H}$
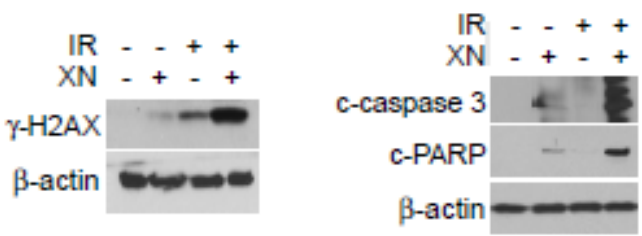

J

K
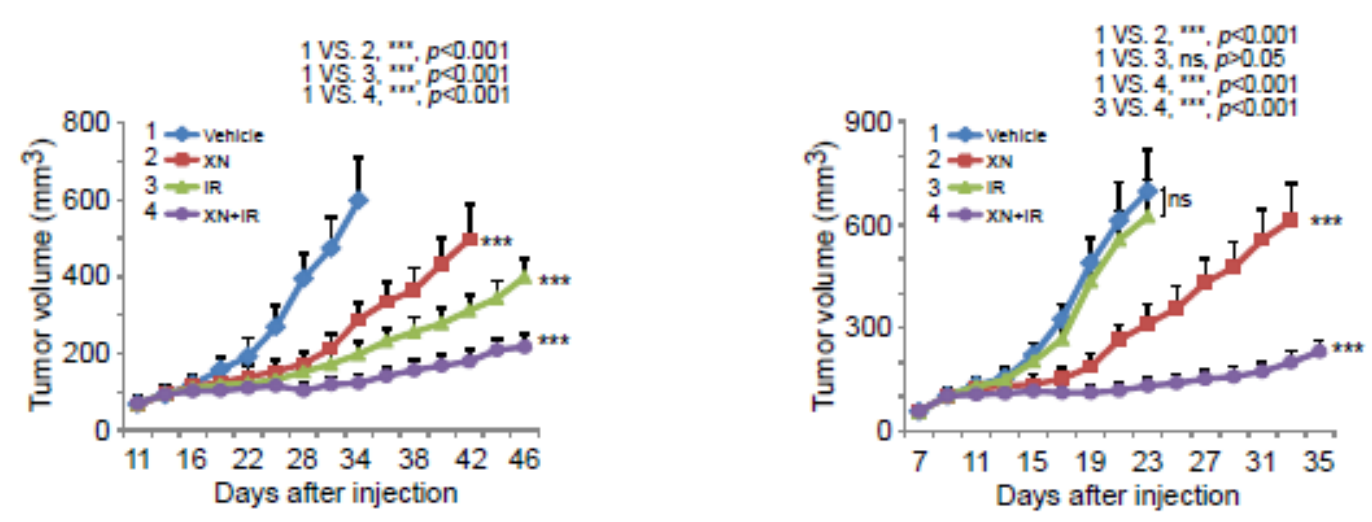

Figure 7

Xanthohumol overcomes radioresistance in OSCC cells. A, IB analysis of the expression of survivin in CAL27/CAL27-IR and SCC25/SCC25-IR cells. B, The effect of irradiation (IR) on cell viability of

CAL27/CAL27-IR cells. CAL27 and CAL27-IR cells were treated with 4 Gy IR, cell viability was examined 72 $h$ later by MTS assay. C, The effect of IR on colony formation of CAL27/CAL27-IR cells. CAL27 and CAL27-IR cells were treated with 4 Gy IR, colony number was examined 2 weeks later. D, IB analysis of 
survivin protein level in CAL27-IR cells treated with xanthohumol (5 $\mu \mathrm{M}), \mathrm{IR}(4 \mathrm{~Gy})$, or a xanthohumol + IR combination. E and $F$, The cell viability $(E)$ and colony formation $(F)$ of CAL27-IR cells treated with xanthohumol, IR, or a xanthohumol + IR combination. $G$ and $H$, Immunofluorescence $(G)$ or IB $(H)$ analysis of $\mathrm{Y}-\mathrm{H} 2 \mathrm{AX}$ in CAL27-IR cells treated with xanthohumol, IR, or a xanthohumol + IR combination. Scale bar, $5 \mu \mathrm{m}$. I, IB analysis of apoptosis in CAL27-IR cells treated with xanthohumol, IR, or a xanthohumol + IR combination. J, In vivo tumorigenesis of CAL27 cells treated with vehicle control, xanthohumol, IR, or a xanthohumol + IR combination. K, In vivo tumorigenesis of CAL27-IR cells treated with vehicle control, xanthohumol, IR, or a xanthohumol + IR combination. ${ }^{\star *} \mathrm{p}<0.001$.

\section{Supplementary Files}

This is a list of supplementary files associated with this preprint. Click to download.

- supplementarymaterials.pdf 